\title{
Perspective
}

\section{Tuning Properties in Silver Clusters}

\author{
Chakra P Joshi, Megalamane S. Bootharaju, and Osman M. Bakr
}

J. Phys. Chem. Lett., Just Accepted Manuscript • DOI: 10.1021/acs.jpclett.5b00934 • Publication Date (Web): 09 Jul 2015

Downloaded from http://pubs.acs.org on July 12, 2015

\section{Just Accepted}

"Just Accepted" manuscripts have been peer-reviewed and accepted for publication. They are posted online prior to technical editing, formatting for publication and author proofing. The American Chemical Society provides "Just Accepted" as a free service to the research community to expedite the dissemination of scientific material as soon as possible after acceptance. "Just Accepted" manuscripts appear in full in PDF format accompanied by an HTML abstract. "Just Accepted" manuscripts have been fully peer reviewed, but should not be considered the official version of record. They are accessible to all readers and citable by the Digital Object Identifier (DOI®). "Just Accepted" is an optional service offered to authors. Therefore, the "Just Accepted" Web site may not include all articles that will be published in the journal. After a manuscript is technically edited and formatted, it will be removed from the "Just Accepted" Web site and published as an ASAP article. Note that technical editing may introduce minor changes to the manuscript text and/or graphics which could affect content, and all legal disclaimers and ethical guidelines that apply to the journal pertain. ACS cannot be held responsible for errors or consequences arising from the use of information contained in these "Just Accepted" manuscripts. 


\title{
Tuning Properties in Silver Clusters
}

\author{
Chakra P. Joshi, Megalamane S. Bootharaju, and Osman M. Bakr* \\ Division of Physical Sciences and Engineering, Solar and Photovoltaics Engineering Research \\ Center, King Abdullah University of Science and Technology (KAUST), Thuwal 23955-6900, \\ Saudi Arabia
}

\begin{abstract}
The properties of Ag nanoclusters are not as well understood as those of their more precious $\mathrm{Au}$ cousins. However, a recent surge in the exploration of strategies to tune the physicochemical characteristics of Ag clusters addresses this imbalance, leading to new insights into their optical, luminescence, crystal habit, metal-core, ligand-shell and environmental properties. In this Perspective, we provide an overview of the latest strategies along with a brief introduction of the theoretical framework necessary to understand the properties of silver nanoclusters and the basis for their tuning. The advances in cluster research and the future prospects presented in this Perspective will eventually guide the next large systematic study of nanoclusters, resulting in a single collection of data similar to the periodic table of elements.
\end{abstract}


TOC graphics

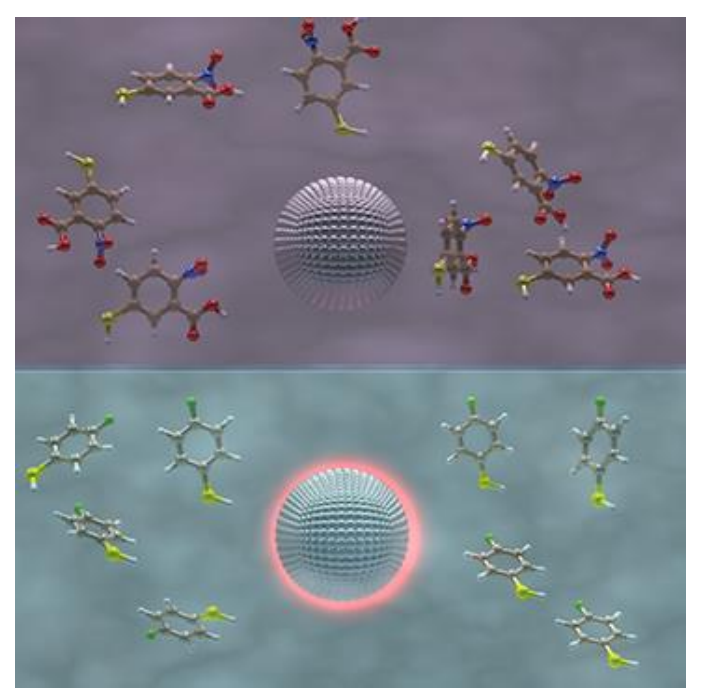

The discovery of the periodic table and the subsequent understanding of atomic properties of elements in the early $20^{\text {th }}$ century initiated many exciting research areas in chemistry. These areas laid the foundation of the cluster field which came into being decades later - i.e. the exploration of the properties of new exotic species consisting of a few to hundreds of atoms known as giant atoms, superatoms, magic clusters, or simply clusters. ${ }^{1-7}$ The uncommon characteristics associated with these clusters were highlighted by Richard Feynman in his famous lecture at the American Physical Society meeting in $1959 .{ }^{1}$ Around the same time, Becker et al. ${ }^{2}$ experimentally demonstrated the possibility for control over atomic/molecular clusters. These clusters are fascinating not only because of their small size but also because of their resemblance to molecules. Later developments of sophisticated instruments and experimental designs in the 1980s helped characterize metal and non-metal clusters, such as $\mathrm{Na}_{n}{ }^{8}$ and fullerene $\mathrm{C}_{60}{ }^{9}$, with unprecedented atomic precision. Despite having the same carbon building block as coal, graphite, and diamond, fullerene $\mathrm{C}_{60}$ exhibits unusual properties, which motivated the cluster community to find analogies in other inorganic systems. In the meantime, advances in theoretical 
and computational modeling of these clusters aided in breathtaking developments in cluster science.

Although metal clusters are considered a part of the broader class of metal nanoparticles (NPs), they have a much shorter history and their manifested characteristics may only be understood based on quantized electronic interactions. However, metal NPs of tens to hundreds of nanometers have been used by artists since the Middle Ages and before to stain glass with colorful hues. Although these artisans were unaware of the exact source and nanoscale nature of the material that helped emanate these beautiful colors, later plasmonic NPs were observed to cause these phenomena. ${ }^{10-11}$

In 1857, Faraday reported the first formal synthesis of metal NPs, i.e., the synthesis of a red Au NP solution. ${ }^{12} \mathrm{He}$ immediately attributed the color of the solution to the size of the Au particles even though he lacked evidence to substantiate this hypothesis. Almost a century later in 1951, with the arrival of electron microscopy, Turkevich et al. ${ }^{13}$ proved Faraday's prediction correct and observed 3-10-nm NPs. Around the same time, McPartlin et al. ${ }^{14}$ reported ultrasmall Au NPs, i.e., $\left[\mathrm{Au}_{11}\left(\mathrm{PPh}_{3}\right)_{7}(\mathrm{SCN})_{3}\right]$ with sizes of $\sim 1 \mathrm{~nm}$. Notably, both Faraday’s Au NPs ${ }^{12}$ and the $\mathrm{Au}_{11}$ cluster ${ }^{14-15}$ produced a similar red solution despite their drastically different sizes. The red appearance of Faraday's NPs ${ }^{11,13}$ was attributed to surface plasmons whereas molecularlike electronic transitions ${ }^{15}$ were thought to cause the reddening of the $\mathrm{Au}_{11}$ cluster solution.

Following the footsteps of Brust et al., ${ }^{16}$ Whetten and co-workers ${ }^{5-6,}{ }^{17}$ reported the synthesis of 5.6, 8.7, 10.4 and $29 \mathrm{kDa}$ Au species/clusters in their work of late-1990s and early2000s, coining the concept of gold NP 'molecules'. However, purification and complete isolation of these $\sim 1-2-\mathrm{nm}$ clusters remained elusive, resulting in a poor estimation of their precise 
molecular formula. ${ }^{5}$ Successive work by the Tsukuda group ${ }^{3}$ in a similar system led to the isolation and unambiguous determination of the molecular formula of several magic goldglutathione $\mathrm{Au}_{m}(\mathrm{SG})_{n}$ species, including $\mathrm{Au}_{10}(\mathrm{SG})_{10}, \mathrm{Au}_{15}(\mathrm{SG})_{13}, \mathrm{Au}_{18}(\mathrm{SG})_{14}, \mathrm{Au}_{22}(\mathrm{SG})_{16}$, $\mathrm{Au}_{22}(\mathrm{SG})_{17}, \mathrm{Au}_{25}(\mathrm{SG})_{18}, \mathrm{Au}_{29}(\mathrm{SG})_{20}, \mathrm{Au}_{33}(\mathrm{SG})_{22}$ and $\mathrm{Au}_{39}(\mathrm{SG})_{24}$. This seminal work in the mid2000s by the Tsukuda group ${ }^{3}$ spurred research on Au clusters and on other metal compositions.

After $\mathrm{Au}, \mathrm{Ag}$ was an obvious candidate because of its low price, largely unexplored properties and shared similarities with $\mathrm{Au}$, despite its notorious lack of stability. A few unconfirmed reports focused on the precise composition of Ag NPs ${ }^{18-19}$ however, in the late2000s, Bakr and Stellacci et al. ${ }^{20}$ discovered Ag NPs with precise formula that displayed nonplasmonic nature. ${ }^{21}$ These non-plasmonic Ag NPs were called IBANs (Intensely and Broadly Absorbing Ag NPs). ${ }^{20}$ Analogous to the $\mathrm{Au}_{m}(\mathrm{SG})_{n}$ species, IBANs have a precise molecular formula of $\left[\mathrm{Ag}_{44}(\mathrm{SR})_{30}\right]^{4-}$ and are $<2 \mathrm{~nm}$ in size. ${ }^{20-21}$ Since then, a handful of precise thiolated Ag clusters have been characterized with atomic precision. ${ }^{42} 2-26$ For example, recent work on the glutathione $\mathrm{Ag}$ system by the Bigioni group led to the isolation of various magic $\operatorname{Ag}_{m}(\mathrm{SG})_{n}$ species that mostly remained uncharacterized except for the $\operatorname{Ag}_{32}(\mathrm{SG})_{19}$ species. ${ }^{23}$ A species with the same optical spectrum as $\mathrm{Ag}_{32}(\mathrm{SG})_{19}$ was assigned by Bertorelle et al. ${ }^{22}$ as $\mathrm{Ag}_{31}(\mathrm{SG})_{19}$. This discrepancy in the mass characterization of similar optical species may be due to the ease of fragmentation and rearrangement of atoms in the gas phase in a mass spectrometer. However, the structure could be decisively determined in the solid state using single-crystal X-ray diffraction if the cluster could be successfully crystallized. Thus, the ground-breaking work of the Kornberg group, ${ }^{27}$ which revealed the crystal structure of $\mathrm{Au}_{102}(p-\mathrm{MBA})_{44}$, paved the way for subsequent crystal structure determination of other metal clusters, such as $\operatorname{Ag}_{44}(p-\mathrm{MBA})_{30}{ }^{28}$ and $\mathrm{Ag}_{44}\left(\mathrm{SPhF}_{2}\right)_{30}{ }^{29}$ with a charge of 4-. This landmark achievement not only revealed the molecular 
structure and metal-thiolate interface of the clusters with unprecedented detail but also provided enormous impetus for the explosive growth in the theoretical and computational fields to understand and predict the fundamental properties associated with the existing and emerging metal clusters.

Decades earlier, before the actual crystallization of the thiol-protected Au/Ag clusters, ${ }^{27-}$ ${ }^{29}$ significant theoretical work was performed to understand and predict the properties of bare metal clusters and was known as the superatom theory. ${ }^{8,30-31}$ These gas-phase metal clusters were assumed to behave like giant atoms and therefore follow the same rules as atoms, such as orbital hybridization, Hund's rule, and the Aufbau principle. Therefore, superatom theory is no different from atomic theory even though superatoms are composed of a few tens to thousands of atoms and have the Jellium foundation. ${ }^{8,} 30$ The Jellium model assumes that positive charges are spread evenly over the sphere and are inert (Figure 1a). ${ }^{8,} 30$ This assumption indeed qualitatively explained various properties related to superatoms. ${ }^{8,31}$
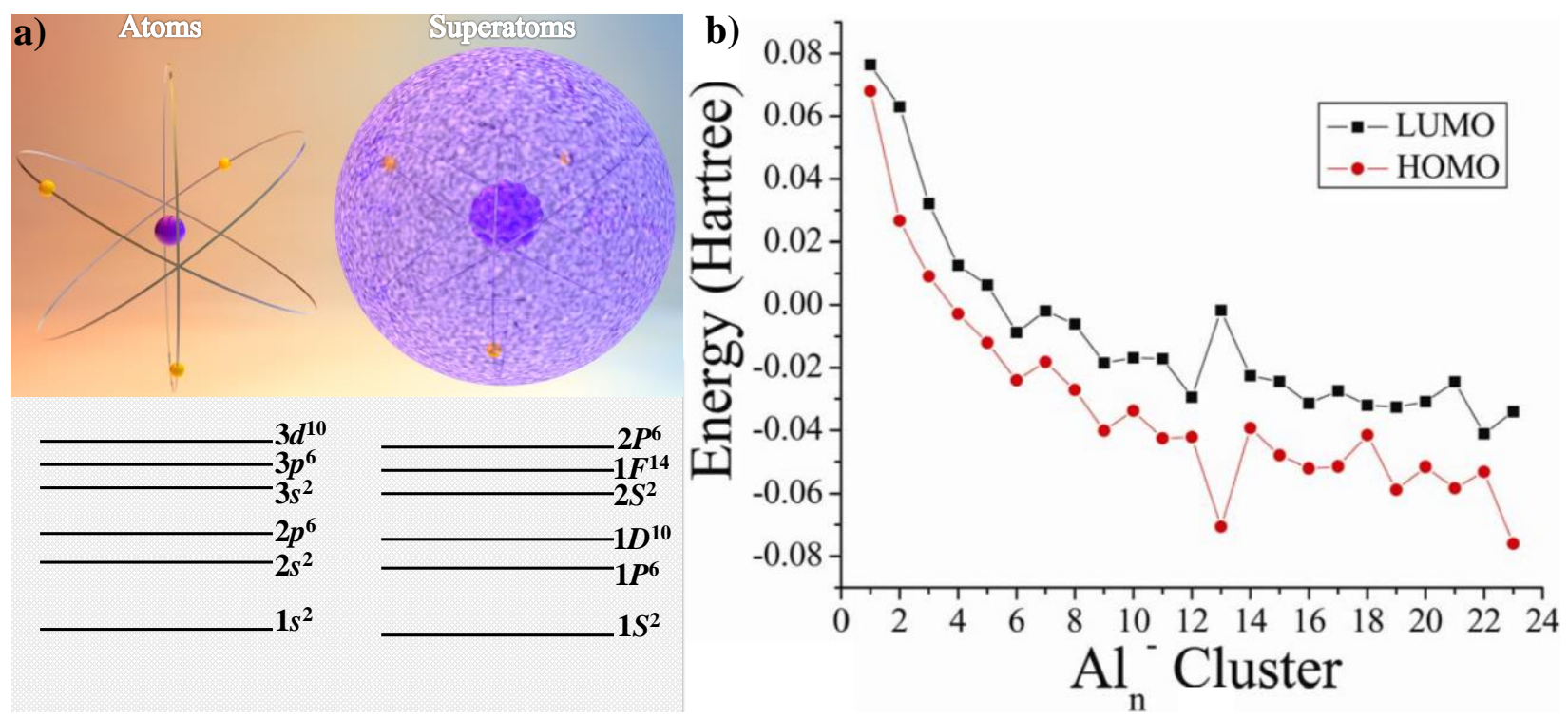

Figure 1. a) A cartoon showing the electron orbitals of an atom (lowercase s, p, d, ‥) and superatom (uppercase $\mathrm{S}, \mathrm{P}, \mathrm{D}, \cdots$ ) with a confined and smeared nuclear region and b) A 
theoretical plot of energy associated with the HOMO and LUMO levels of $\mathrm{Al}_{n}{ }^{-}$clusters as a function of size. ${ }^{32}$ Figure 1 (b) reprinted from ref. $\left[{ }^{32}\right]$ with written permission.

For instance, consider the $\mathrm{Na}_{\mathrm{n}}$ cluster. Sodium has one $3 s$ electron in its valence shell and is known to form bare $\mathrm{Na}_{n}$ clusters in the gas phase. ${ }^{8}$ Following the observation that some $\mathrm{Na}_{n}$ species were more stable than others, Knight and coworkers ${ }^{8}$ rationalized this discrepancy based on the electronic shell-closing rule of the superatom theory, where large HOMO-LUMO gaps created by a closed shell conferred stability to bare $\mathrm{Na}_{n}$ clusters analogous to those of inert gases. The resemblance between the filling of the superatomic orbitals of these bare metal clusters to the filling of atoms inspired Häkkinen's $\operatorname{group}^{33}$ to extend this idea to ligand-protected metal clusters that follow the electronic shell closure rule described below: $:^{31,33}$

$1 \mathrm{~S}^{2}\left|1 \mathrm{P}^{6}\right| 1 \mathrm{D}^{10}\left|2 \mathrm{~S}^{2} 1 \mathrm{~F}^{14}\right| 2 \mathrm{P}^{6} 1 \mathrm{G}^{18}\left|2 \mathrm{D}^{10} 3 \mathrm{~S}^{2} 1 \mathrm{H}^{22}\right| \cdots \cdots$

where the vertical lines indicate a shell-closure with a very large HOMO-LUMO gap. The uppercase characters $\mathrm{S}, \mathrm{P}, \mathrm{D}, \mathrm{F}, \cdots \cdots$ represent the angular momentum quantum numbers of the superatomic orbitals, and $1,2,3, \cdots \cdots$ correspond to radial nodes. Using the electronic shellclosing rule, one can obtain closed shells for $n_{e}=2,8,18,20,34,40,58, \cdots \cdots$, where $n_{e}$ is the total free electrons available in a cluster. ${ }^{33}$ For example, the stability of $\mathrm{Na}_{40}$ and $\mathrm{Al}_{13}{ }^{-}$clusters ${ }^{8,34}$ can be explained based on the electronic shell closure. The $\mathrm{Na}_{40}$ and $\mathrm{Al}_{13}{ }^{-}$clusters ${ }^{8,34}$ contain 40 $\mathrm{Na}\left(3 s^{1}\right)$ and $13 \mathrm{Al}\left(3 s^{2} 3 p^{1}\right)$ atoms, resulting in a total of 40 and 39 valence electrons, respectively. The inclusion of a negative charge associated with the $\mathrm{Al}_{13}{ }^{-}$cluster results in a total of 40 valence electrons. This electron count corresponds to a closed shell $\left(n_{e}=40\right)$ with a configuration of $1 \mathrm{~S}^{2}, 1 \mathrm{P}^{6}, 1 \mathrm{D}^{10}, 2 \mathrm{~S}^{2}, 1 \mathrm{~F}^{14}, 2 \mathrm{P}^{6}$ imparting exceptional stability to these gas phase clusters (Figure 1b). 
Although the electronic shell-closing rule is useful in explaining the stability of clusters, it also suggests the existence of a limited number of stable clusters with closed electronic shells. Research work by Brust and coworkers on Au-thiolates provided some insights to stabilize clusters' metal core with ligands. ${ }^{16}$ However, this idea was later viewed more generally as describing a metal core that can coordinate, deposit, or access electrons from an electron reservoir in the form of surface ligands to maintain a coveted closed electronic shell, thereby ensuring stability. The idea of ligands as a surrounding electron reservoir then spread to Ag and other metals, ${ }^{4-5,19}$ where ligands are believed to satisfy the dangling bonds present on a cluster. ${ }^{16}$ By considering ligand and metal-core interactions, Walter et $a l .{ }^{33}$ proposed an electron count magic rule for ligand-protected metal clusters. According to the rule, for the ligand-protected Ag clusters of the form $\left[\mathrm{C}_{x} \mathrm{Ag}_{N} \mathrm{~L}_{M}\right]^{\mathrm{z}}$, where $\mathrm{C}$ is a Lewis-base-type coordinating ligand that does not withdraw electrons but rather bonds to a metal core through a dative bond (e.g., phosphine and amine) and $\mathrm{L}$ is a one-electron-withdrawing ligand (e.g., thiol), the electron-count rule is ${ }^{33}$

$$
n_{e}=N v-M-z,
$$

where $v$ is the atomic valence of $\mathrm{Ag}, N$ is the number of core $\mathrm{Ag}$ atoms, $M$ and $x$ are the number of respective ligands and $z$ is the overall charge of the cluster. The application of the electroncount rule to condensed-phase metal clusters explains why $\left[\mathrm{Au}_{25}(\mathrm{SG})_{18}\right]^{-35}$ and $\left[\mathrm{Ag}_{44}(\mathrm{SR})_{30}\right]^{4-28-}$ ${ }^{29}$ with $n_{e}=8$ and 18 -electron cores, respectively, are very stable as their total free electron counts correspond to closed electronic shells. ${ }^{33}$

Despite the success of the electronic shell closure, the presence of conspicuous mass peaks of bare metal clusters, such as $\mathrm{Na}_{12}, \mathrm{Na}_{26}$, and $\mathrm{Na}_{38}$, in the gas phase ${ }^{8}$ and stable ligandprotected metal clusters, such as $\mathrm{Au}_{38}(\mathrm{SR})_{24}{ }^{36}, \mathrm{Ag}_{32}(\mathrm{SG})_{19}{ }^{23,} 37$ and $\mathrm{Ag}_{15}(\mathrm{SG})_{11}{ }^{22}$ in the condensed phase appear to be exceptions to the rule. However, Clemenger attributed the stability 
of these $\mathrm{Na}_{n}$ clusters to their non-spherical shape caused by a distortion analogous to the JahnTeller effect. ${ }^{31,} 38$ Indeed, $\mathrm{Au}_{38}(\mathrm{SR})_{24}$ with a 14-electron core was later crystallized ${ }^{36}$ and observed to have a non-spherical shape (prolate, face-fused bi-icosahedron). Similar nonspherical shapes are expected for $\mathrm{Ag}_{32}(\mathrm{SG})_{19},{ }^{23} \mathrm{Ag}_{31}(\mathrm{SG})_{19}$, and $\mathrm{Ag}_{15}(\mathrm{SG})_{11}{ }^{22}$ clusters.

In addition to electronic shell closing, geometric shell closing is also applied to explain the cluster stability. Depending on the geometric shape, e.g., cubic, tetrahedral, octahedral, or icosahedral, certain numbers of building units are required to form a closed geometry. Consider a cubic shape. It is not possible to construct a cube out of 26 or 28 spheres; this goal requires precisely 27 atoms (i.e., $3^{3}$ ). This type of precise requirement can be observed in the fullerene $\mathrm{C}_{60}$ with icosahedral symmetry. ${ }^{9}$ Fullerene is known to have a closed geometry and hence is very stable. ${ }^{9}$ Removing or adding an extra carbon atom to the $\mathrm{C}_{60}$ surface would destabilize the geometry and therefore requires significant energy. Likewise, metal clusters also prefer icosahedral symmetry at the core. ${ }^{728-29}$ The number of atoms required to make a closed icosahedral geometry can be determined using Mackay’s ${ }^{39}$ icosahedral sequence $S_{n}=10 n^{2}+2$, where $S_{n}$ represents the surface atoms of the $n^{\text {th }}$ shell, from which one can acquire a closed geometric shell configuration corresponding to $1,13,55,147,309,561, \cdots \cdots$ core atoms. Leuchtner et $a l .{ }^{34}$ experimentally demonstrated the importance of geometric shell by studying the reactivity of $\mathrm{Al}_{13}{ }^{-}, \mathrm{Al}_{23}{ }^{-}$and $\mathrm{Al}_{37}{ }^{-}$clusters (representing 40, 70, and 112 electrons, respectively) toward oxygen. Although all three clusters have a closed electronic shell, $\mathrm{Al}_{13}{ }^{-}$was observed to be the most stable ${ }^{34}$ because of its closed geometric shell (13-atom icosahedron, Figure $1 \mathrm{~b}$ ). Similar stability was reported for $\mathrm{Ag}_{13}{ }^{-}$clusters. ${ }^{40}$ The open geometry associated with $\mathrm{Al}_{23}{ }^{-}$and $\mathrm{Al}_{37}{ }^{-34}$ would sustain steps on these cluster surfaces, lowering the work function and hence 
reducing the stability. ${ }^{41}$ For practical realization of these theories, actual clusters must be synthesized.

\section{Syntheses of Ag clusters}

The synthesis protocol for ligand-protected $\mathrm{Ag}$ clusters is rather straightforward. Generally, a Ag salt is mixed with a thiol ligand in a suitable solvent system to form a silverthiolate complex. The silver-thiolate complex is then reduced with a strong reducing agent, such as $\mathrm{NaBH}_{4}$, to produce $\mathrm{Ag}$ clusters that are successively washed and then re-dispersed in an appropriate solvent. Other synthetic routes, such as solid-state, ${ }^{42}$ ligand-exchange, ${ }^{43}$ and antigalvanic processes, ${ }^{44}$ are also available. Some aqueous syntheses produce polydispersed Ag clusters such as $\operatorname{Ag}_{m}(\mathrm{SG})_{n}$ clusters ${ }^{4,19}$, whose purity and monodispersity are achieved either via cyclic reduction under oxidative conditions or through polyacrylamide gel electrophoresis (PAGE). By contrast, the monodispersity of organic soluble clusters, especially alloys, is improved via thermal processing ${ }^{29}$ or chromatography ${ }^{45-47}$. Nevertheless, by tailoring the properties of the solvents and ligands, some remarkable success has been achieved in obtaining a truly single-sized product of Ag clusters in both aqueous and organic phases using one-pot synthesis approaches..$^{20,28-29,48-49}$ This scaling up of cluster synthesis with no known upper limit (irrespective of pure or doped clusters, Figure 2) reminds us of the molecular nature of these clusters and could facilitate the application of clusters in photocatalysis ${ }^{50}$ and sensing ${ }^{24-25}$ over large areas in addition to improving the fundamental understanding of their properties. 
a)

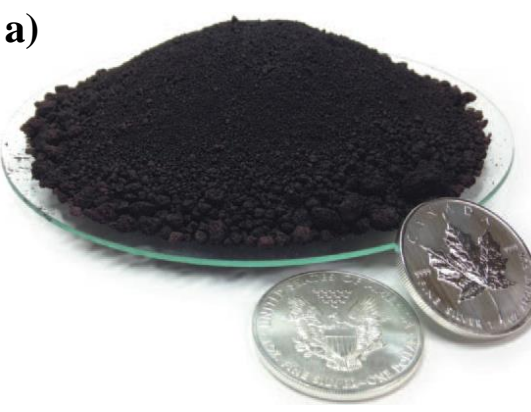

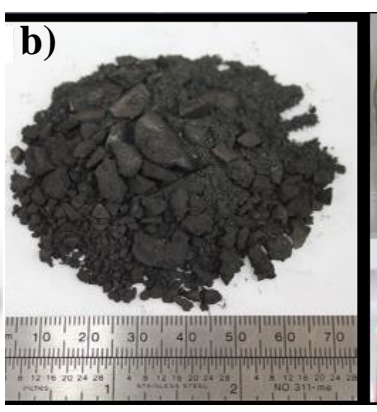

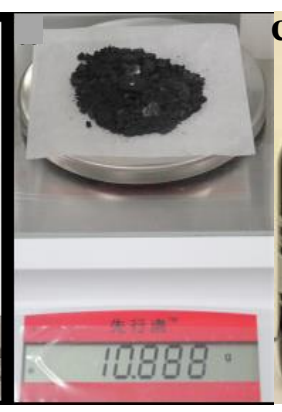

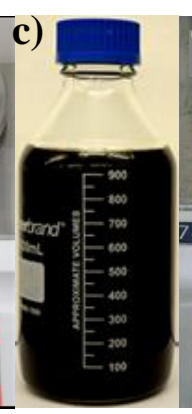

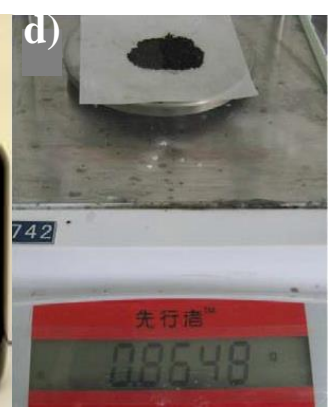

Figure 2. Scaled-up final single-sized product of a) $\left[\mathrm{Ag}_{44}(p-\mathrm{MBA})_{30}\right]^{4-}, 140 \mathrm{~g}^{28} ;$ b) $\left[\mathrm{Ag}_{44}(\mathrm{SPhF})_{30}\right]^{4-}, 10.89 \mathrm{~g}^{29} ;$ c) $\left[\mathrm{Ag}_{44}(\mathrm{MNBA})_{30}\right]^{4-}$ clusters, $172 \mathrm{mg}$ in $1 \mathrm{~L}$ of $1 \mathrm{M}$ aqueous $\mathrm{NaOH}^{48}$; and d) $\mathrm{Au}_{25} \mathrm{Ag}_{2}(\mathrm{PET})_{18}$ alloy cluster, $0.86 \mathrm{~g}^{49}$. Adapted from refs. [28-29, 48-49] with written permission.

\section{Factors involved in tuning the properties of Ag clusters}

The physical and chemical properties of clusters are affected by their cores, ligands, and environments. By varying these factors, it is possible to tune the cluster properties. To illustrate, consider the family of magic $\mathrm{Ag}_{m}(\mathrm{SG})_{n}$ clusters. ${ }^{4}{ }^{51}$ While synthesizing the family of glutathione Ag clusters, the same environment was sustained in a reaction vessel; however, clusters purified from the gel exhibited distinct optical properties. This behavior is possible because of the different core sizes, i.e., the number of Ag atoms changed from one cluster to another. However, it is expected that the change in core atoms would subsequently lead to a different number of ligands to enclose the core appropriately, which was also observed with $\mathrm{Au}_{m}(\mathrm{SG})_{n}{ }^{3}$ and $\mathrm{Au}_{m}(\mathrm{PET})_{n}{ }^{7}$ clusters (PET: 2-phenylethanethiol), where a quantitative relationship was mapped between the cluster cores and their optical properties.

The properties arising from the cluster core can also be engineered by doping or alloying the cluster with other metal atoms, resulting in combined properties from both metal atoms. In general, doped clusters are synthesized by reducing a suitable ratio of different metal salt 
precursors in the presence of a ligand. The Zheng group ${ }^{29}$ reported the doping of $\left[\mathrm{Ag}_{44}\left(\mathrm{SPhF}_{2}\right)_{30}\right]^{4-}$ with 12-Au atoms, producing completely different properties. For example, the optical spectrum of $\left[\mathrm{Ag}_{44}\left(\mathrm{SPhF}_{2}\right)_{30}\right]^{4-}$ contained eight peaks, including two shoulder peaks, and the cluster was stable for $<4 \mathrm{hrs}^{29}$ whereas the spectrum of its 12 -Au doped counterpart, $\left[\mathrm{Ag}_{32} \mathrm{Au}_{12}\left(\mathrm{SPhF}_{2}\right)_{30}\right]^{4-}$, contained only two prominent and three shoulder peaks, and the cluster was able to survive $>12$ hrs. under the harsh conditions of $80{ }^{\circ} \mathrm{C}^{29}$ In contrast, the Dass group ${ }^{52}$ reported selective replacement of $12-\mathrm{Au}$ atoms of a $\left[\mathrm{Au}_{25}(\mathrm{PET})_{18}\right]^{-}$core with $\mathrm{Ag}$, producing a mixture of $\left[\mathrm{Au}_{25-x} \mathrm{Ag}_{x}(\mathrm{PET})_{18}\right]^{-}$alloy clusters. These researchers also noticed a significant change in the optical properties of $\left[\mathrm{Au}_{25}(\mathrm{PET})_{18}\right]^{-}$clusters after doping. Fortunately, the core size was preserved in both cases after being alloyed with different metal atoms. Like Au, Ag mingles with other metals, such as $\mathrm{Pd}, \mathrm{Pt}$, and $\mathrm{Ni}$, at the nanoscale, producing alloy clusters with various compositions, such as $\left[\mathrm{Ag}_{5} \mathrm{Pd}_{4}(\mathrm{SePh})_{12}\right]^{-45} \mathrm{Ag}_{4} \mathrm{Pt}_{2}(\mathrm{DMSA})_{4},{ }^{47}$ and $\mathrm{Ag}_{4} \mathrm{Ni}_{2}(\mathrm{DMSA})_{4}{ }^{46}$. The syntheses of materials of this type with different metal precursors are challenging and often lead to a mixture of clusters with different metal ratios, which are extremely difficult to purify.

Galvanic exchange is also used for alloying clusters. In this process, usually a metal cluster is mixed with salt or a cluster of another metal, causing a redox reaction to occur. Using this technique, the Pradeep group ${ }^{53}$ succeeded in producing a luminescent alloy cluster $\mathrm{Ag}_{7} \mathrm{Au}_{6}(\mathrm{MSA})_{10}$ by reacting a mixture of $\mathrm{Ag}_{7}(\mathrm{MSA})_{7}$ and $\mathrm{Ag}_{8}(\mathrm{MSA})_{8}$ clusters with $\mathrm{Au}^{3+}$ ions of aqueous $\mathrm{HAuCl}_{4}$. These researchers proposed that the $\mathrm{Au}^{3+}$ ions first formed $\mathrm{Au}(\mathrm{I})$-thiolates with excess MSA (mercaptosuccinic acid) that subsequently reacted with the cluster mixture $\operatorname{Ag}_{7-8}$, forming the luminescent cluster $\mathrm{Ag}_{7} \mathrm{Au}_{6}(\mathrm{MSA})_{10}$. In addition to galvanic exchange, the antigalvanic process was also observed to be equally effective for alloying the clusters. The Wu group $^{49}$ succeeded in alloying $\left[\mathrm{Au}_{25}(\mathrm{PET})_{18}\right]^{-}$clusters with Ag simply by mixing $\left[\mathrm{Au}_{25}(\mathrm{PET})_{18}\right]^{-}$ 
clusters with $\mathrm{Ag}^{+}$in $\mathrm{AgNO}_{3}$ solutions, producing luminescent $\left[\mathrm{Au}_{25} \mathrm{Ag}_{2}(\mathrm{PET})_{18}\right]^{-}$clusters. In this case, the $\left[\mathrm{Au}_{25}(\mathrm{PET})_{18}\right]^{-}$clusters reduced the $\mathrm{Ag}^{+}$to $\mathrm{Ag}$ atoms, thereby resulting in successful alloying. Although both the galvanic and anti-galvanic processes produced luminescence clusters, in both cases, the cluster size unfortunately changed because of the alloying, which complicates the determination of the most crucial factors affecting the cluster properties. Nonetheless, this reactivity of the clusters in the galvanic/anti-galvanic process stems from the reduction potential of the metals, which decreases drastically with the core size. ${ }^{54}$ For instance, the standard reduction potential of bulk $\mathrm{Ag}$ changed from $+0.79 \mathrm{~V}$ to $-1.8 \mathrm{~V}$ when its size reached an isolated $\mathrm{Ag}$ atom in aqueous solution. ${ }^{54}$ This dramatic change in the reduction potential makes clusters attractive for the galvanic and anti-galvanic processes.

The environment where the clusters originate and/or are placed is also an important factor that contributes to their overall characteristics. Some environmental factors, such as temperature, ${ }^{55} \mathrm{pH}^{22,}{ }^{51}$ and the solvent, ${ }^{56}$ are known to change the cluster properties. For example, the Ras group ${ }^{56}$ demonstrated a dramatic change in the luminescence of Ag clusters, supposedly $\mathrm{Ag}_{2}$ and $\mathrm{Ag}_{3}$, by changing the solvent type or using co-solvents. Although the reported $\mathrm{Ag}_{2}$ and $\mathrm{Ag}_{3}$ are more likely the fragments (in the mass measurement during mass spectrometry) of a larger Ag cluster, the observed luminescence tunability highlighted the

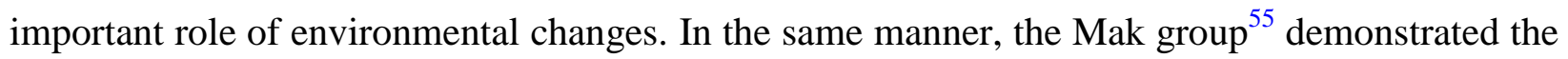
luminescence tunability of $\operatorname{Ag}_{12}$ clusters. Likewise, the Stellacci group ${ }^{20-21}$ demonstrated the optical tunability of $\mathrm{Ag}_{44}$ clusters simply by raising the temperature (Figure 3a). The optical tunability of $\mathrm{Ag}_{44}$ clusters with temperature actually caused Ag-core growth, producing plasmonic NPs. ${ }^{20}$ Despite the aforementioned environmental factors, such as solvatochromism ${ }^{56}$ 
and thermochromism, ${ }^{55}$ a complete understanding of how the environment affects the cluster properties has not yet been achieved.

a)

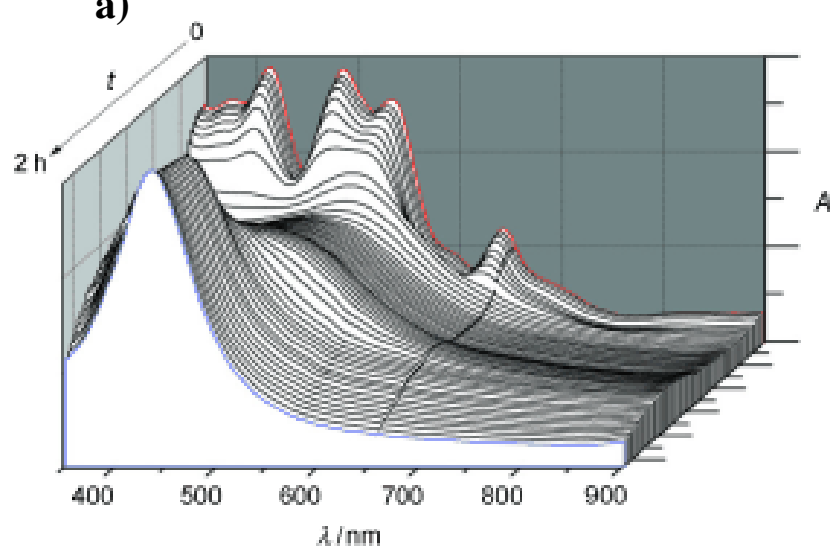

b)

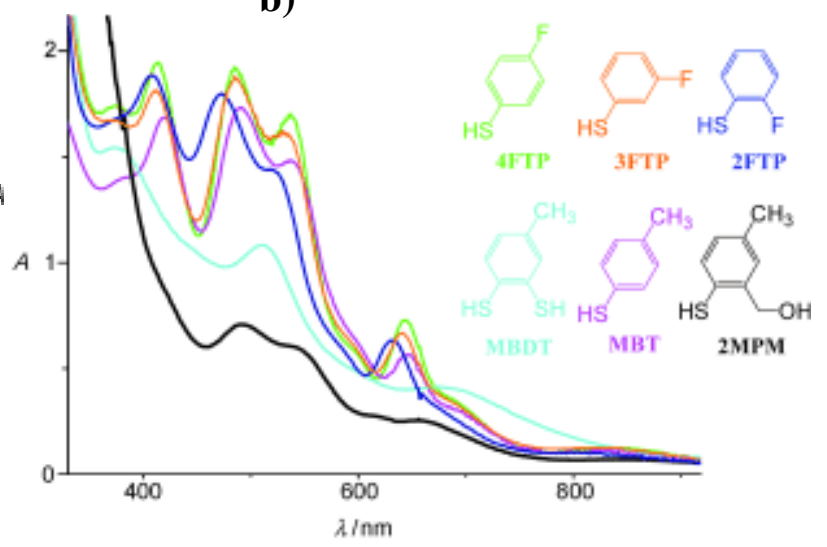

Figure 3. a) Optical spectra of $\mathrm{Ag}_{44}(\mathrm{SR})_{30}{ }^{4-}$ clusters at $90{ }^{\circ} \mathrm{C}$ as a function of time ${ }^{20}$ and b) effect of various aryl-thiol ligands on the optical spectra of Ag clusters. ${ }^{20}$ Reprinted from ref. $\left[{ }^{20}\right]$ with written permission.

The ligand is another factor that changes the cluster properties. The compatibility of a cluster toward a particular solvent largely depends on the ligand. Moreover, the cluster stability depends on how well the ligands guard a sensitive core from the surrounding environment. A few examples of ligand effects on Ag clusters are highlighted here, starting with a demonstration by Bakr et $a l .{ }^{20}$ Figure $3 \mathrm{~b}$ shows that six different aryl-thiol ligands produced similar optical spectra to Ag; however, the ligand with a substitution next to its thiol (-SH) group was observed to affect the optical spectrum the most. Using the HSPhF ligand, our group ${ }^{43}$ quantitatively replaced the ligand shell of $\left[\mathrm{Ag}_{44}(\mathrm{MNBA})_{30}\right]^{4-}$ clusters while preserving the core (Figure 4). By performing this modification, we solubilized the aqueous $\mathrm{Ag}_{44}$ clusters into the organic phase and endowed them with luminescence. The report of Bootharaju et al. $^{57}$ revealed reversible tuning of the cluster size and solubility of Ag clusters via ligand effects. These researchers transformed $\mathrm{Ag}_{32}(\mathrm{SG})_{19}$ clusters ${ }^{37}$, reassigned to $\mathrm{Ag}_{35}(\mathrm{SG})_{18},{ }^{57}$ into $\left[\mathrm{Ag}_{44}(\mathrm{SPhF})_{30}\right]^{4-}$ and vice 
versa by exploiting the differences in the binding energy of the $\mathrm{Ag}-\mathrm{S}$ bond arising from different thiol ligands. In addition to tuning the size, other properties, such as chirality, can also be introduced to a cluster via the ligands, as described by Cao et al. ${ }^{58}$ These researchers induced chirality in an achiral $\mathrm{Au}_{25}$ cluster by capping it with a chiral ligand, such as $(R / S)$-2-amino-3phenylpropane-1-thiol, which could be useful in modern optics. Chirality in Ag clusters has yet to be explored; however, a handful of reports probed chiral-thiol-protected Ag clusters. ${ }^{19,59}$

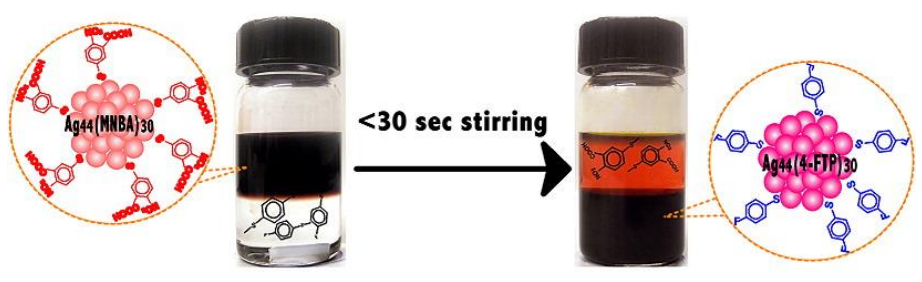

Figure 4. Phase transfer of aqueous $\left[\mathrm{Ag}_{44}(\mathrm{MNBA})_{30}\right]^{4-}$ clusters into dichloromethane (DCM) using $\mathrm{HSPhF}$ as a ligand and tetraphenylphosphonium bromide (TPPB) as a counter-ion. ${ }^{43}$ Reprinted from ref. $\left[{ }^{43}\right]$ with written permission.

Ligands can also select a particular cluster size (especially with Ag) even though the actual mechanism is not yet fully known. This capability presents a rare opportunity to study the properties of clusters of the same-core-size with various ligands. For example, selenophenol was used to reversibly produce $\left[\mathrm{Ag}_{44}(\mathrm{SePh})_{30}\right]^{4-}$ clusters. ${ }^{60}$ The oxidation of $\left[\mathrm{Ag}_{44}(\mathrm{SePh})_{30}\right]^{4-}$ with $\mathrm{H}_{2} \mathrm{O}_{2}$ produced a $\mathrm{Ag}(\mathrm{I})$-selenolate complex whose successive reduction with $\mathrm{NaBH}_{4}$ yielded the original $\left[\mathrm{Ag}_{44}(\mathrm{SePh})_{30}\right]^{4-}$ clusters. ${ }^{60}$ This finding demonstrates that the HSePh ligand selects the particular cluster size $\left(\mathrm{Ag}_{44}\right)$ that is the most thermodynamically stable among clusters of other sizes. Our recent work using thiols instead of selenols ${ }^{43,57}$ also supports this finding. We examined the size-selection in a different manner; instead of exploiting reductive-oxidative conditions, as performed by the Pradeep group, we used the ligand-exchange method described 
in Figure 4. Here, aqueous $\left[\mathrm{Ag}_{44}(\mathrm{MNBA})_{30}\right]^{4-43}$ and $\mathrm{Ag}_{35}(\mathrm{SG})_{18}$ clusters ${ }^{57}$ were used as starting materials and were then phase transferred into DCM by the HSPhF ligand. Remarkably, after ligand exchange, we obtained the same $\left[\mathrm{Ag}_{44}(\mathrm{SPhF})_{30}\right]^{4-}$ cluster reported earlier ${ }^{20,29}$ in both cases. These results demonstrated the size-selection by the HSPhF ligand is independent of the original cluster size. It is speculated that the steric effects of the ligands along with the unique synergism of the metal, nature of ligand, and solvent environment are responsible for the selection of the thermodynamically stable cluster size.

Bidentate and tridentate ligands are also interesting for tuning cluster properties, where simultaneous attachment of the bidentate/tridentate thiol or phosphine groups to a metal core could create a rigidity/strain within a cluster. The use of monodentate aryl-thiols, such as $p$-MBA or $\mathrm{HSPhF}$, is known to produce hollow icosahedral core $\mathrm{Ag}_{44}$ clusters, ${ }^{28-29}$ whereas the use of bidentate alkyl-dithiols, such as $\mathrm{NH}_{4}\left[\mathrm{~S}_{2} \mathrm{P}(\mathrm{O} i \mathrm{Pr})_{2}\right]^{26}$, was observed to produce non-hollow icosahedral-core $\mathrm{Ag}_{21}$ clusters even though both the clusters contain three-dimensional protecting units. Nevertheless, a fair comparison can be made only with bidentate aryl-dithiols, whose effects on cluster properties have yet to be observed but are also expected to produce nonhollow-core Ag clusters.

Mixed ligand protection also changes the cluster properties. For instance, the use of phosphine in addition to a thiol ligand completely changed the spherical shape of a purely thiolated $\mathrm{Au}_{25}$ core $^{35}$ to a rod shape. ${ }^{61-62}$ This overall shape change led to poor performance of the rod-shaped $\mathrm{Au}_{25}$ cluster in catalysis, ${ }^{63}$ such as the oxidation of styrene and hydrogenation of $\alpha, \beta$-unsaturated benzalacetone. By contrast, in the case of $\mathrm{Ag}$, the use of the co-ligands phosphine ${ }^{64}$ and diphosphine ${ }^{65}$ with the same thiol $\left(\mathrm{HSPhF}_{2}\right)$ produced $\mathrm{Ag}_{14}{ }^{64}$ and $\mathrm{Ag}_{16}{ }^{65}$ clusters instead of $\mathrm{Ag}_{44}{ }^{29}$, which is expected when the $\mathrm{HSPhF}_{2}$ ligand is used alone. In the former case, 
phosphine preserved the $\mathrm{Au}_{25}$ core while changing its shape; however, in the latter case, the phosphine roughly preserved the sphericality of the $\mathrm{Ag}_{44}$ core ${ }^{29}$ while shrinking its size. These changes caused by the mixed ligand systems provide an opportunity to study the fundamental changes in the properties of clusters caused by mixed ligands. A theoretical study of the ligand effects on clusters by the Jiang group ${ }^{66}$ revealed that the stronger van der Waals forces and steric effect through a ligand are critical to the cluster stability and other related properties. Yacaman's group $^{67}$ also observed that the ligand was one of the key players affecting the cluster absorption properties.

\section{Understanding the properties of Ag nanoclusters}

Absorption spectroscopy is routinely used in the characterization of organic molecules and organometallic complexes because it can distinguish between different conformers and resonances. Because the number of allowed transitions is constrained by selection rules, absorption spectra can also provide valuable information about the symmetry, band gap, and electronic/geometrical structure associated with a particular system. This basic knowledge is also useful for distinguishing metal clusters with different sizes. Several gel purified magic $\operatorname{Au}_{m}(\mathrm{SG})_{n}$ clusters $^{3}$ were first distinguished from each other based on their unique optical spectra, which was confirmed by their mass measurements, thus firmly establishing absorption spectroscopy as the first indispensable diagnostic tool for characterization. Similar work involving differentiating $\mathrm{Ag}_{m}(\mathrm{SG})_{n}$ clusters (Figure 5) ${ }^{4,23,51}$ was also performed via absorption spectroscopy even though most of these $\operatorname{Ag}_{m}(\mathrm{SG})_{n}$ clusters await mass characterization, which highlights the importance of absorption spectroscopy in cluster identification. Absorption spectra arise deep within the cluster structure due to the combined effects of the core, ligand, and environment. Some progress in this regard has been made by correlating the experimental absorption spectrum of a $\left[\mathrm{Au}_{25}(\mathrm{PET})_{18}\right]^{-}$ 
cluster with its crystal structure in 2008 by Zhu et al. ${ }^{35}$ via time-dependent (TD) density functional theory (DFT). The appearance of the highly structured optical spectrum of $\left[\mathrm{Au}_{25}(\mathrm{PET})_{18}\right]^{-}$, unlike the $\sim 525 \mathrm{~nm}$ peak of Au plasmons, was attributed to intra-band $(s p \rightarrow s p)$ and inter-band $(d \rightarrow s p)$ transitions within the cluster. ${ }^{35}$ In other words, the transitions arising at the red end of the spectrum are attributed to the metal core, whereas the blue end are dominated by both metal and ligand characteristics, i.e., $-\mathrm{S}-\mathrm{Au}-\mathrm{S}-\mathrm{Au}-\mathrm{S}-$ motifs. $^{35}$ Based on this information, the Aikens group ${ }^{20}$ predicted the size and crystal structure of IBANs in 2009. Neither the size nor the crystal structure was precisely known at the time; however, these researchers simulated the absorption features of IBANs and predicted a size of 25 atoms (i.e., $\left.\mathrm{Ag}_{25}\right){ }^{20}$ Later, mass spectrometry and single-crystal X-ray diffraction measurements proved otherwise, i.e., IBANs are $\mathrm{Ag}_{44}$ clusters. ${ }^{21,28-29}$ Although the theoretical prediction using DFT did not match the experimental data for IBANs, it helped the theoretical community tremendously in further refining their predictions, such as in 2010 , when Lopez-Acevedo et al. ${ }^{68}$ predicted the crystal structure of $\mathrm{Au}_{38}(\mathrm{SR})_{24}$ using DFT before the publication of the actual experimental structure $^{36}$.

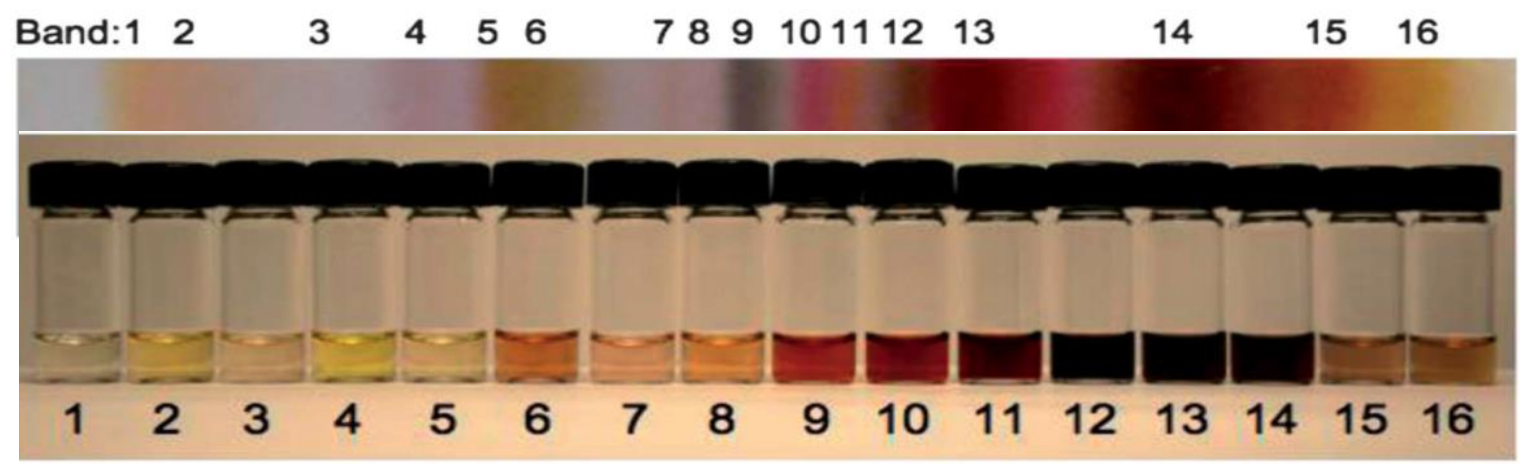

Figure 5. Extracted gel bands of $\operatorname{Ag}_{m}(\mathrm{SG})_{n}$ clusters (top panel) and their corresponding aqueous solutions (bottom panel). Except for band 6, which is $\operatorname{Ag}_{32}(\mathrm{SG})_{19}$, the molecular formula for 
other bands are not known with atomic precision. ${ }^{51}$ Adapted from ref. $\left[{ }^{51}\right]$ with written permission.

Despite some success in deciphering the absorption spectrum of the cluster, significant work lies ahead in predicting the crystal structures and origin of such a spectrum. Determining and predicting the most influencing factors to tune the optical spectra of clusters remains a challenge. Some qualitative studies on tuning the optical spectra of Ag clusters based on the ligand, temperature, ${ }^{20}$ and core size ${ }^{4,51}$ have been reported previously. Although it remains a daunting task to propose the crystal structure from an optical spectrum of the known mass species, attempts have been pursued to predict the crystal structures ${ }^{22,69}$ for existing and emerging Ag clusters, including doped clusters ${ }^{46-47}$ whose validity awaits actual crystallization of the cluster.

In addition to absorption, clusters also display luminescence behavior, by which it might be possible to predict the cluster size if the emission is due to the bandgap (Eg) transition. This potential was first recognized by $\mathrm{Kubo}^{70}$ in 1962 with a simple scaling factor of $\mathrm{E}_{f} / \mathrm{N}$, i.e., the energy gap in small metal clusters scales as $1 / \mathrm{N}$, where $\mathrm{N}$ is the total number of atoms, and $\mathrm{E}_{f}$ is the Fermi energy of silver $5.49 \mathrm{eV}^{31,71}$. The absence of fluorescence in bulk metals is due to overlapping energy states that provide numerous non-radiative pathways for the decay of an excited electron. ${ }^{72}$ However, because of the presence of discrete energy states, small metal clusters exhibit fluorescence ${ }^{73}$. Early work by the Whetten group ${ }^{72}$ attributed intraband $(s p \rightarrow s p)$ transitions within a metal core to the photoluminescence of $<2$-nm-sized Au clusters. Subsequent work from the same group on the precise cluster $\mathrm{Au}_{28}(\mathrm{SG})_{16},{ }^{5,74}$ later corrected to $\mathrm{Au}_{25}(\mathrm{SG})_{18}{ }^{3}$ provided similar arguments for the fluorescence/phosphorescence albeit with some implications of the ligand effects. ${ }^{74}$ While studying the fluorescent properties of Au clusters, 
Zheng et $a l .{ }^{75}$ (Knight et $a l .{ }^{8}$ for bare $\mathrm{Na}_{n}$ clusters) empirically established a scaling factor of $\mathrm{E}_{f} / \mathrm{N}^{1 / 3}$ between the energy gap and the number of atoms in ligand-protected metal clusters based on the Jellium model. The Zheng et $a l .{ }^{75}$ relation was effective up to 20 -atom Au clusters, beyond which correction factors were needed to explain the emission and cluster-size relationship.

In favor of $\mathrm{Ag}$ clusters, the Dickson group ${ }^{76}$ first reported fluorescent $\mathrm{Ag}$ clusters encapsulated by dendrimers. Huang and Murray's ${ }^{18}$ work pointed to the inter-band recombination (between $d$ and $s p$ ) as a fluorescence source for Ag clusters. Although the exact origin of the fluorescence in precise Ag clusters remains disputable, Cathcart et al. ${ }^{19}$ and Bakr et $a l .^{20-21}$ reported additional luminescence Ag clusters protected by glutathione, cysteine, and arylthiols. It is logical to assume that the visible luminescence from a relatively small-size cluster will be blueshifted compared with a large cluster because the HOMO-LUMO gap changes with the size. However, counter-intuitive observations (see Table 1), such as visible luminescence from a large $\mathrm{Ag}_{152}{ }^{69}$ cluster compared with small IR-luminescence $\left[\mathrm{Ag}_{44}(\mathrm{SPhF})_{30}\right]^{4-20}$ cluster and a blueshift in the luminescences of $\mathrm{Ag}_{9}(\mathrm{SG})_{6}{ }^{77}$ and $\mathrm{Ag}_{15}(\mathrm{SG})_{11}{ }^{22}$ compared with those of $\mathrm{Ag}_{8}(\mathrm{MSA})_{8}{ }^{24}$ and $\mathrm{Ag}_{11}(\mathrm{SG})_{7}{ }^{25}$, add some other parameters that affect the cluster-size and emission relationship. These luminescence-altering factors can be due ligand and surface state transitions, in addition to contributions from the cluster's surrounding environment. For example, Li et $a .^{78}$ and $\mathrm{Xu}$ et $a .^{55}$ demonstrated the luminescence change by understanding the temperature effects on precise Ag clusters, whereas Díez et al. ${ }^{56}$ observed that the solvent rather than the size affected the emission. Recent work from the Jin group ${ }^{79}$ on Au clusters emphasized the ligand, as they discovered that ligand $\rightarrow$ metal charge transfer (LMCT) either via the $\mathrm{Au}-\mathrm{S}$ bond or through the electron-rich atoms/groups (e.g., $\mathrm{N}, \mathrm{O},-\mathrm{COOH},-\mathrm{NH}_{2}$ ) was responsible for 
the fluorescence. Similar LMCT in Ag clusters was observed by Pelton et al. ${ }^{80}$ while studying transient-absorption spectroscopy of IBANs. A summary of the photophysical properties associated with some of the precise Ag clusters with their characterization techniques is provided in Table 1.

Table 1. A selection of atomically precise thiol- and thiol-phosphine-protected Ag clusters and their photophysical properties.

\begin{tabular}{|c|c|c|c|c|c|}
\hline S.N. & Chemical formula & Excitation (nm) & Emission (nm) & Characterization & Ref. \\
\hline 1 & $\mathrm{Ag}_{152}(\mathrm{PET})_{60}$ & 375 & 800 & MALDI & 69 \\
\hline 3 & $\mathrm{Ag}_{44}(\mathrm{SPhF})_{30}^{4-}$ & 596,643 & 1375 & single-crystal & 29 \\
\hline 4 & $\mathrm{Ag}_{35}(\mathrm{SG})_{18}$ & 420,500 & 650 & ESI-MS & 57 \\
\hline 5 & $\mathrm{Ag}_{32}(\mathrm{SG})_{19}$ & 420,500 & 680 & ESI-MS & 23 \\
\hline 6 & $\mathrm{Ag}_{32}(\mathrm{DPPE})_{5}\left(\mathrm{SPhF}_{3}\right)_{24}{ }^{2-}$ & 360 & 440 & single-crystal & 65 \\
\hline 7 & $\mathrm{Ag}_{25}(\mathrm{DHLA})_{14}$ & 355 & 680 & ESI-MS & 81 \\
\hline 8 & $\mathrm{Ag}_{16}(\mathrm{SG})_{9}$ & 489 & 647 & ESI-MS & 77 \\
\hline 9 & $\mathrm{Ag}_{16}(\mathrm{DPPE})_{4}\left(\mathrm{SPhF}_{2}\right)_{14}$ & 360 & 440 & single-crystal & 65 \\
\hline 10 & $\operatorname{Ag}_{15}(\mathrm{SG})_{11}$ & 470 & 665 & ESI-MS & 22 \\
\hline 11 & $\mathrm{Ag}_{14}\left(\mathrm{SPhF}_{2}\right)_{12}\left(\mathrm{PPh}_{3}\right)_{8}$ & 360 & 536 & single-crystal & 64 \\
\hline 12 & $\mathrm{Ag}_{11}(\mathrm{SG})_{7}$ & 440 & 705 & ESI-MS & 25 \\
\hline 13 & $\mathrm{Ag}_{9}(\mathrm{MSA})_{7}$ & 625 & 720 & ESI-MS & 42 \\
\hline 14 & $\operatorname{Ag}_{9}(\mathrm{SG})_{6}$ & 379 & 495 & ESI-MS & 77 \\
\hline 15 & $\mathrm{Ag}_{8}(\mathrm{MSA})_{8}$ & 550 & 650 & ESI-MS & 24 \\
\hline 16 & $\mathrm{Ag}_{7}(\mathrm{MSA})_{7}$ & 350 & 440 & ESI-MS & 24 \\
\hline
\end{tabular}


The luminescence data in Table 1 of Ag clusters were analyzed using the scaling factors reported by $\mathrm{Kubo}^{70}$ and Zheng et al. ${ }^{75}$ (Figure 6) to study the size-dependent emission properties. Both the Kubo and the Zheng et al. models are found to be unsuitable for explaining the entire data and therefore are unable to predict the relationship between size and emission of $\mathrm{Ag}$ clusters. However, unlike $\mathrm{Au}$ where the model of Zheng et al. is somewhat reasonable, ${ }^{75}$ significant deviation is observed in the size range of $\sim 8-15$ and $\geq 44$-atom in Ag clusters. Although the origin of such discrepancy is a complex problem with many potential variables and assumptions and is beyond the scope of this article; nevertheless, it can be understood that the photoluminescence may not originate only from the band-gap of clusters, which limits our ability to predict Ag cluster size spectroscopically with the emission energy versus Eg relation.

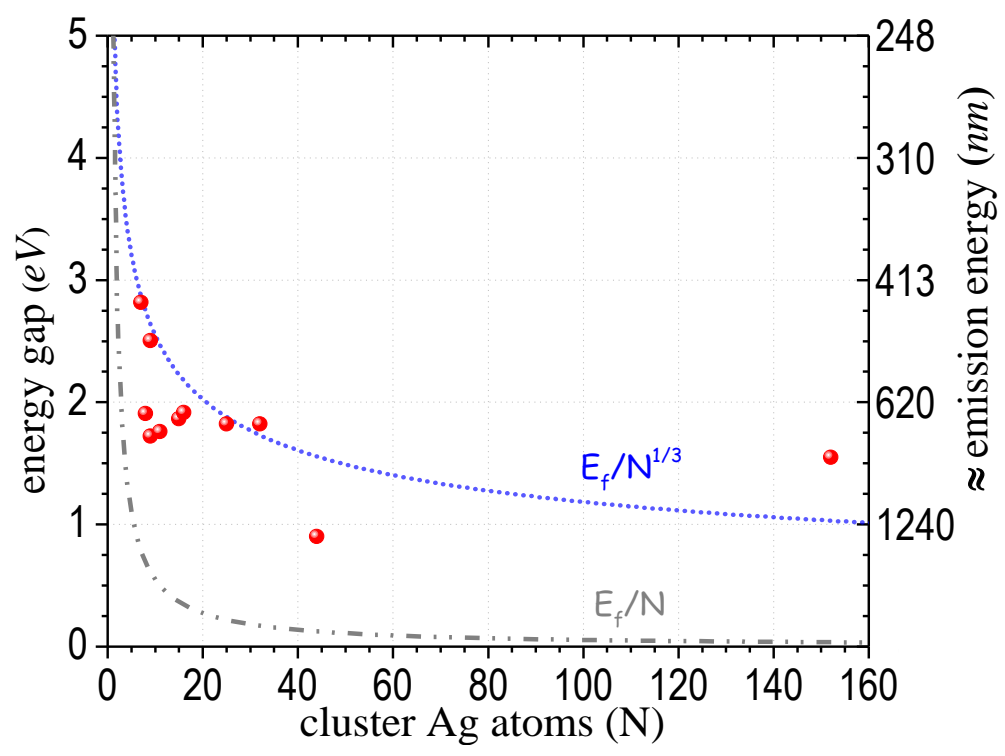

Figure 6. Correlation of the emission energy of Ag cluster size as predicted by Kubo (gray, $\mathrm{E}_{f} / \mathrm{N}$ ) and Zheng et al. (blue, $\mathrm{E}_{f} / \mathrm{N}^{1 / 3}$ ) scaling factors. The red spheres represent the actual emission energy of the thiolated Ag clusters. 
Also, when discussing spectroscopic properties related to Ag clusters, caution should be exercised because $\mathrm{Ag}$ is prone to oxidation and is sensitive to light. Relatively few Ag clusters are reported (Table 1), and some might be impure and unstable ${ }^{69}$. Trace impurities in Ag cluster samples with other sizes, especially the luminescent ones arising from oxidation or other processes from the existing clusters during spectroscopic measurements, could significantly affect emission spectrum. This effect adds uncertainty to the interpretation of the data and therefore should be considered prior to estimation of $\mathrm{Ag}$ cluster size via emission $\propto \mathrm{E} g$ relation.

In order to minimize the decomposition of Ag clusters with light in optical spectroscopy and to identify materials close to their native states, mass spectrometry (MS) with softer ionization method is essential. The Whetten group used laser desorption ionization (LDI) MS for the characterization of Au clusters. ${ }^{5-6,17}$ However, because of the significant fragmentations from the LDI, relatively softer techniques with high resolution, such as matrix-assisted laser desorption ionization (MALDI) and electrospray ionization (ESI), are more prevalent today. The ESI MS, in particular, is preferred over MALDI because it neither uses light (laser) nor a solidified sample with matrix. The Tsukuda ${ }^{3}$ and Griffith groups ${ }^{23}$ characterized magic-size $\mathrm{Au}_{m}(\mathrm{SG})_{n}$ and $\mathrm{Ag}_{32}(\mathrm{SG})_{19}$ clusters, respectively, using ESI MS. The Griffith group observed that the Ag thiolates were more fragile and prone to fragmentation than their $\mathrm{Au}$ counterparts. ${ }^{23}$ Nevertheless, MS is one of the most important tools for the characterization of clusters where the molecular formula of the compound of interest is important for identification and crystallization poses a significant challenge.

Crystallization ensures purity of the material by consolidating molecules in a dense space where single-crystal X-ray diffraction can reveal the ultimate atomic coordinates in 3D space. Detection of the intact cluster or its fragments in MS sometimes make interpreting a mass 
spectrum quite challenging because several processes, such as rearrangement, coordination, and fragmentation, occur in parallel in the gas phase. Most of these gas-phase metal clusters are difficult to crystallize or manipulate because they either change their properties or lose identity when they contact other species. Growing a single crystal from the solution phase of the cluster could be a possibility, although crystallization is challenging. Despite these challenges, there are reports of the crystallization of pure-thiol and mixed-ligand Ag clusters. ${ }^{28-29,64-65}$

Similar to molecules, clusters prefer certain types of crystal habits. For example, graphite and diamond are composed of the same carbon building blocks; however, their respective crystal habits are completely different, i.e., tabular and octahedral. This tunability of the crystal habit results in new properties for materials. A recent report by Yao et al. ${ }^{82}$ brings this promise to the cluster community, as shown in Figure 7. These researchers were able to perform a crystal habit transition from a rhombohedral to an octahedral state for the same $\left[\operatorname{Ag}_{44}(p-\mathrm{MBA})_{30}\right]^{4-}$ system by swapping counter-ions ${ }^{82}$. In this case, the directionality provided by the counter-ions $\mathrm{H}^{+}$via $\mathrm{H}-$ bonding was disrupted with $\mathrm{Cs}^{+}$ions, which led to the change in the crystal habit. The ability to swap counter-ions with other metal-cations, such as $\mathrm{Ca}^{2+}$ and $\mathrm{Al}^{3+}$, would allow engineers to construct new 3D shapes using $\left[\mathrm{Ag}_{44}(\mathrm{SR})_{44}\right]^{4-}$ as building blocks in the future, which could result in dramatically useful properties at the macro-scale that have already been achieved at the microscale $^{28,82}$. 

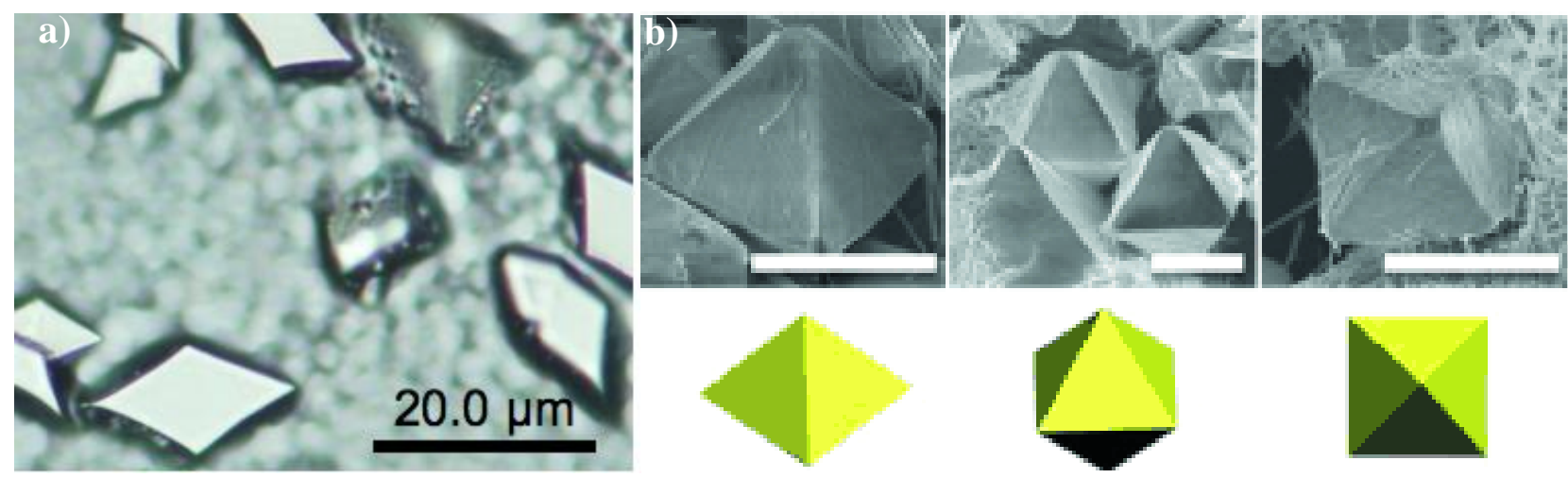

Figure 7. Crystals of $\left[\mathrm{Ag}_{44}(p-\mathrm{MBA})_{30}\right]^{4-}$ clusters a) with a rhombus shape crystallized from a dimethylformamide (DMF) solution with a completely protonated ligand as observed under an optical microscope $\mathrm{e}^{28}$ and $\mathbf{b}$ ) electron micrograph of the octahedron-shaped crystals grown from dimethylsulfoxide $(\mathrm{DMSO}) /$ water using $\mathrm{Cs}^{+}$counter-ions $^{82}$ (scale bar $\left.=10 \mu \mathrm{m}\right)$. Adapted from refs. ${ }^{28}$ and ${ }^{82}$ with written permission.

Manifestation of fundamental properties such as the optical-activity and reactivity is key to understanding metal clusters better and can ultimately be achieved using single-crystal X-ray diffraction for both aqueous ${ }^{28}$ and organic $^{29}$ soluble Ag clusters. Surprisingly, single-crystal Xray diffraction revealed a completely different protecting layer for $\mathrm{Ag}$ clusters than for $\mathrm{Au}$ clusters, where mono (-S-Au-S-) and dimeric (-S-Au-S-Au-S-) motifs were predominant (Figure 8). ${ }^{35-36}$
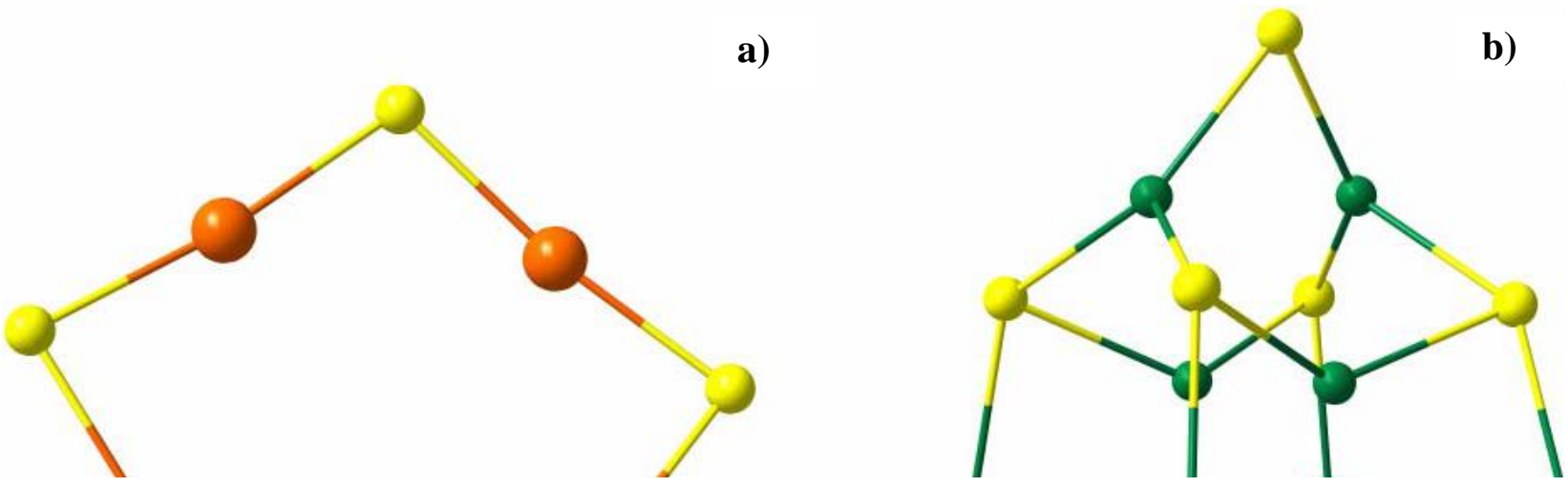
Figure 8. Structure of the cluster-protecting motifs $\mathrm{Au}_{2} \mathrm{~S}_{3}$ (left) and $\mathrm{Ag}_{2} \mathrm{~S}_{5}$ (right) observed in $\mathrm{Au}$ and Ag clusters, respectively. ${ }^{28-29,} 35$ Color legend of spheres: $\mathrm{Au}-$ orange, Ag-green, and Syellow. Adapted from ref. $\left[{ }^{29}\right]$ with written permission.

As observed in Figure 8, the Au clusters are protected with one-dimensional motifs whereas the Ag clusters crystallized so far are protected with three-dimensional motifs. Although the ubiquitous nature of the three-dimensional $\mathrm{Ag}_{2} \mathrm{~S}_{5}$ motif has yet to be proven, it can be argued that the many one-dimensional motifs would provide better coverage for a cluster core than the three-dimensional motif. This hypothesis is also supported by the fact that $\left[\operatorname{Ag}_{44}(p-\mathrm{MBA})_{30}\right]^{4-}$ contains $\sim 50 \%$ void space $^{28}$ in the crystal volume, making it highly affected by its surrounding, which could explain the relatively low stability of Ag clusters compared with Au clusters. In stark contrast, our observations of year-long ambient stability in other Ag clusters, such as aqueous $\left[\mathrm{Ag}_{44}(\mathrm{MNBA})_{30}\right]^{4-48}$ and $\mathrm{Ag}_{35}(\mathrm{SG})_{18}{ }^{57}$, clearly indicate the opposite physicochemical behavior.

\section{Perspectives}

The syntheses of Ag clusters involve multi-step and hours-long processes ${ }^{20,29}$ with few exceptions $^{28}$. For instance, the synthesis of $\left[\mathrm{Ag}_{44}(\mathrm{SR})_{30}\right]^{4-}$ requires days based on the protocol of Bakr et al. ${ }^{20}$ whereas a similar composition can be obtained in a one-pot synthesis in an hour using the procedure described by Desireddy et $a l^{28}$. This shortening of the synthesis time is crucial for materials processing and applications on industrial scales. Nevertheless, the key factors behind this drastic reduction in synthesis time have not been seriously considered. In 
addition, in $\operatorname{Ag}_{m}(\mathrm{SG})_{n}$ clusters, what factors determine the values of $m$ and $n$ remains a mystery both experimentally and theoretically and therefore require attention.

Silver has received less attention than has gold from the beginning even though it is inexpensive. This inferiority of silver over gold was due to its susceptibility to oxidation. However, at the nanoscale, $\mathrm{Ag}$ is not as susceptible to oxidation as indicated by the resistance of some $\mathrm{Ag}$ clusters, such as $\mathrm{Ag}_{35}(\mathrm{SG})_{18}{ }^{57}$ and $\left[\mathrm{Ag}_{44}(\mathrm{MNBA})_{30}\right]^{4-48}$. Many magic clusters in the $\mathrm{Au}_{m}(\mathrm{SG})_{n}$ family $^{3}$ have been successfully characterized with atomic precision because they are stable. Years have passed since the isolation of $20+$ magic $\operatorname{Ag}_{m}(\mathrm{SG})_{n}$ clusters; ${ }^{4}$ however, few ${ }^{22-23}$ of these clusters have been characterized. This lack of progress in the characterization of $\mathrm{Ag}$ clusters lies in either cluster stability or instrumental limitations. Stability appears to be a critical factor despite the significant technical know-how acquired from the characterization of analogous $\mathrm{Au}_{m}(\mathrm{SG})_{n}$ clusters because the instability associated with $\mathrm{Ag}$ clusters can ruin a sample, as decayed products accumulate over time, resulting in poor data and confusion. For example, four research groups independently working on the same glutathione Ag system detected $\operatorname{Ag}_{m}(\mathrm{SG})_{n}$ species with very similar absorption features that were assigned as $\mathrm{Ag}_{35}(\mathrm{SG})_{18}{ }^{57}, \mathrm{Ag}_{32}(\mathrm{SG})_{19},{ }^{23} \mathrm{Ag}_{31}(\mathrm{SG})_{19},{ }^{22}$ and $\mathrm{Ag}_{16}(\mathrm{SG})_{9}{ }^{77}$.

Although some clues for improving the stability of Ag clusters were revealed from a single-crystal structure of $\mathrm{Ag}_{44}{ }^{28-29}$ and other $\mathrm{Ag}$ species ${ }^{64-65}$, significant work needs to be performed before actual manipulation of the Ag cluster stability can be achieved. Among all available $\mathrm{Ag}$ species, ${ }^{20,28-29,48}$ aqueous $\left[\mathrm{Ag}_{44}(\mathrm{MNBA})_{30}\right]^{4-}$ is observed to be the most stable with an 18-electron core. However, this cluster undergoes rapid ligand exchange with different arylthiols in a matter of seconds, producing less-stable species, such as $\left[\mathrm{Ag}_{44}(\mathrm{SPhF})_{30}\right]^{4-}$ and $\mathrm{Ag}_{44}(2-$ naphthalenethiol) ${ }_{30}{ }^{4-}$ with a $\mathrm{Ag}_{44}$ core intact. ${ }^{43}$ A question remains unanswered: Why would the 
cluster sacrifice its stability to migrate into a less-stable state? Arguments that an excess ligand pushes the equilibrium in favor of the ligand exchange are reasonable. However, reversibility was not observed when excess MNBA ligand was used to obtain the original $\left[\operatorname{Ag}_{44}(\mathrm{MNBA})_{30}\right]^{4-}$ from the $\left[\mathrm{Ag}_{44}(\mathrm{SPhF})_{30}\right]^{4-}$ clusters in our experiments.

In addition, unlike $\mathrm{Au}$, where the same ligand PET can produce different size $\mathrm{Au}_{m}(\mathrm{PET})_{n}$ clusters, ${ }^{7} \mathrm{Ag}$ is known to form the same $\mathrm{Ag}_{44}$ cluster with different aryl thiols. ${ }^{20,}{ }^{43}$ This limits our ability to diversify cluster size; however, a subtle yet important empirical factor for cluster size tuning is often lost. For tuning the size of Ag clusters, researchers should look at those aryl thiols that have substitution adjacent to the thiol group. This subtle change in ligands could unlock the key to producing Ag clusters of different sizes, which needs to be considered.

Another concern is the superatom theory. The electronic and geometric shell closure ideas of the superatom theory represent significant theoretical advancements in explaining the stability associated with clusters. However, some clusters do not have closed structures (Figure 9), do not obey superatom theory but are very stable. Therefore, the superatom theory requires modification to include clusters with open shells. Moreover, having a closed electronic shell does not guarantee that the cluster is a superatom even though it is one criterion. For example, the $\left[\mathrm{Au}_{23}\left(\mathrm{SC}_{6} \mathrm{H}_{11}\right)_{16}\right]^{-}$cluster ${ }^{7,83}$ has an $8 \mathrm{e}^{-}$core, analogous to the $\left[\mathrm{Au}_{25}(\mathrm{PET})_{18}\right]^{-}$cluster; however, DFT analysis based on the experimental crystal structure proved that this cluster was not a superatom. In this case, where the superatom theory has a limited use, Clemenger ${ }^{38}$ suggested $^{3}$ that the clusters would undergo distortion to lower their energies; however, a concrete theory is not available yet. Thus, we should be cautious regarding the superatom theory. Deeper understanding may imply that it is feasible in principle to synthesize arbitrary $\operatorname{Ag}_{m}$ clusters (where $m=1,2,3,4, \cdots$ ) although these clusters may vary in the stability. In the future, we 
could have numerous $\mathrm{Ag}_{m}$ clusters with various properties that could go beyond the periodic table of elements to meet our needs. We believe that emerging Ag clusters may follow a particular trend described by the stability curve presented in Figure 9.

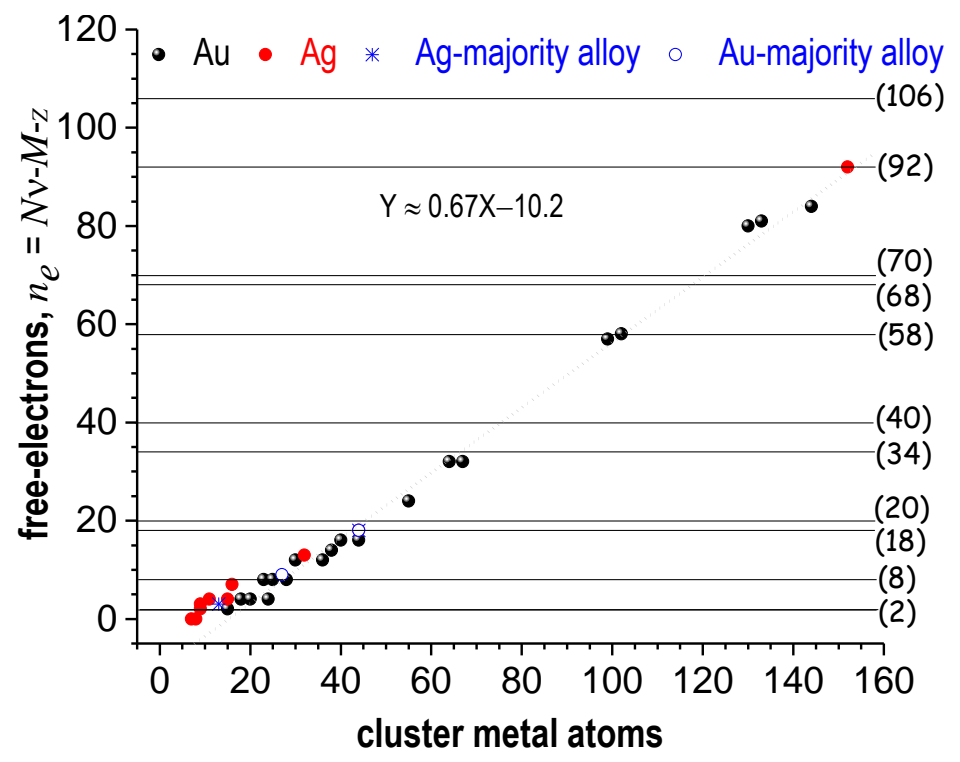

Figure 9: Stability belt of ligand-protected metal clusters obtained after analysis of the free electrons present in the thiol-protected $\mathrm{Ag}_{m} \mathrm{~L}_{n}$ and $\mathrm{Au}_{m} \mathrm{~L}_{n}$, and their alloys. The numbers inside the parentheses indicate electron-shell closure, and the dotted line is the actual fit to $\mathrm{Au}_{m} \mathrm{~L}_{n}$ clusters with a slope of $\approx 2 / 3$ (data compiled from Table 1 and refs. $\left[{ }^{7},{ }^{49},{ }^{53},{ }^{29}\right.$ and $\left.{ }^{84}\right]$ )

It is apparent from Figure 9 that ligand-protected metal clusters follow a certain trend described by the plot of $n_{e}$ versus cluster metal atoms. Notably, the clusters populate themselves around a line with a slope of $2 / 3$. Therefore, the magic size clusters maintain a magic ratio of approximately 2 free electrons for every 3 metal atoms with some intercept value (Figure 9). We expect that emerging Ag clusters would follow the trend described by the stability curve because it would be difficult to synthesize a mono-thiol protected clusters that deviate considerably from the projection of the stability curve. We also studied the plot of $\left(n_{e}-|\mathrm{z}|\right)$ versus cluster core atoms 
(not shown) but did not find much difference because the majority of clusters are neutral. Regardless of the superatom theory, this stability curve can serve as a guide for predicting the sizes of $\mathrm{Ag}_{m}$ clusters that can be synthesized, which could be studied like the periodic table of elements. Furthermore, the stability curve also suggests a threshold of a cluster size of $\sim 15$ atoms, beyond which the core atom count in a cluster would always be greater than the ligand count.

Finally, impending chaos is on the horizon for the systematic study and organization of existing and emerging ligand-protected metal clusters. Therefore, a healthy debate on this matter is expected in the scientific community. Attempts toward the systematic study of bare gas-phase metal clusters in a 3D periodic table have been discussed in the literature ${ }^{85-86}$ however, this effort has not been made for ligand-protected metal clusters. Our views in this regard are presented below.

Natural elements are arranged in the standard form of the periodic table as a function of their increasing atomic numbers such that no two elements have the same position in the $7 \times 18$ grid table (Figure 10, top panel). However, the arrangement of clusters is different; these structures possess a few hundred atoms clinging together, resulting in an additional dimension that is not needed for atoms. Moreover, existing and emerging clusters would easily outnumber the total elements by a large margin, thus complicating their systematic study, given the number of ways that atoms can be arranged in a 3D cluster space.

Nevertheless, placing $\operatorname{Ag}_{m} \mathrm{~L}_{n}$ clusters in a periodic table similar to Mendeleev's is an option. However, finding a reasonable basis for the arrangement of clusters in the most meaningful manner is challenging. We have many candidates for bases: the total atomic number 
or weight, cluster electron configuration, cluster energy, electronegativity, length, etc. Using the total atomic number or weight as a basis, which is obtained by summing the contributions from all the atoms present in a cluster, appears unsuitable because it would produce a very large number. Superatom/cluster electronic configuration, i.e., categorizing clusters into S, P, D, F, G, ... $\cdots$ blocks is possible; however, some clusters do not follow the superatom theory. The exclusion of non-superatoms or superatoms with zero free electrons or in a negative state (i.e., the case of a greater ligand than metal count) could be a serious problem in this case. An arrangement based on either the total energy or electronegativity of a cluster is less likely because of the fractional numbers and the high probability of similar values for many different clusters. Arranging clusters according to their length is promising because the nanoscale properties depend on the length scale. However, defining a precise length is difficult because of the variability in cluster shapes. Therefore, we think that organizing clusters based on the core metal atom count would simplify the task as we can have very precise numbers $1,2,3,4,5, \cdots \cdots$ similar to the atomic numbers in the periodic table of elements. Depending on the shape, size, and cluster properties, we do expect the same-size clusters to be assigned to a single or multiple cells. However, the length and width of the periodic table for $\operatorname{Ag}_{m} \mathrm{~L}_{n}$ clusters currently remain changeable due to inadequate data.

Despite these issues, the question arises of how the periodic table of clusters would look when they are arranged as a function of increasing core atoms. Certainly, it would be much different from the periodic table of elements (Figure 10, top panel). Unlike the periodic table of elements, periodicity will be lost with clusters. Therefore, the future periodic table of clusters would look like a megapixel photograph, where a pixel would represent either a superatom or a non-superatom cluster. This photograph of clusters (abbreviated here as "clusterograph") would 
have local or regional similarities among different clusters across the entire grid (highlighted in red, yellow, green, blue and violet) but no recurring periodicity. Furthermore, in contrast to the periodic table of elements, similar superatom clusters, such as $\left[\mathrm{Ag}_{44}(\mathrm{SPhF})_{30}\right]^{4-}$, $\left[\mathrm{Ag}_{44}\left(\mathrm{SPhF}_{2}\right)_{30}\right]^{4-}$ and $\left[\mathrm{Ag}_{44}\left(\mathrm{SPhF}_{3}\right)_{30}\right]^{4-}$, would be given a single cell even though each cluster contains a different ligand. We believe that most elements in the periodic table of elements such as $\mathrm{Cu}, \mathrm{Au}, \mathrm{Pd}$, and $\mathrm{Pt}$ would have their own clusterograph as we demonstrate here for $\mathrm{Ag}$ in Figure 10, bottom panel. Interpreting these clusterographs would be more appropriate for computers than for humans.

\begin{tabular}{|c|c|c|c|c|c|c|c|c|c|c|c|c|c|c|c|c|c|c|}
\hline $\begin{array}{l}1 \\
\text { H }\end{array}$ & & & & & & & & & & & & & & & & & & $\begin{array}{l}2 \\
\mathrm{He}\end{array}$ \\
\hline $\begin{array}{l}3 \\
\mathbf{L i}\end{array}$ & $\begin{array}{l}4 \\
\mathrm{Be}\end{array}$ & & & & & & & & & & & & $\begin{array}{l}5 \\
\text { B }\end{array}$ & $\begin{array}{l}6 \\
C\end{array}$ & $\begin{array}{l}7 \\
\text { N }\end{array}$ & $\begin{array}{l}8 \\
0\end{array}$ & $\begin{array}{l}9 \\
\text { F }\end{array}$ & $\begin{array}{l}10 \\
\mathrm{Ne}\end{array}$ \\
\hline $\begin{array}{l}11 \\
\mathrm{Na}\end{array}$ & $\begin{array}{l}12 \\
\mathrm{Mg}\end{array}$ & & & & & & & & & & & & $\begin{array}{l}13 \\
\text { Al }\end{array}$ & $\begin{array}{l}14 \\
\mathrm{Si}\end{array}$ & $\begin{array}{l}15 \\
P\end{array}$ & $\begin{array}{l}16 \\
S\end{array}$ & $\begin{array}{l}17 \\
\text { Cl }\end{array}$ & $\begin{array}{l}18 \\
\mathrm{Ar}\end{array}$ \\
\hline $\begin{array}{l}19 \\
\text { K }\end{array}$ & $\begin{array}{l}20 \\
\mathrm{Ca}\end{array}$ & $\begin{array}{l}21 \\
\text { Sc }\end{array}$ & $\begin{array}{l}22 \\
\mathrm{Ti}\end{array}$ & $\begin{array}{l}23 \\
\text { V }\end{array}$ & $\begin{array}{l}24 \\
\mathrm{Cr}\end{array}$ & $\begin{array}{l}25 \\
\text { Mn }\end{array}$ & $\begin{array}{l}26 \\
\mathrm{Fe}\end{array}$ & $\begin{array}{l}27 \\
\text { Co }\end{array}$ & $\begin{array}{l}28 \\
\mathrm{Ni}\end{array}$ & & & $\begin{array}{l}30 \\
\mathrm{Zn}\end{array}$ & $\begin{array}{l}31 \\
\text { Ga }\end{array}$ & $\begin{array}{l}32 \\
\mathrm{Ge}\end{array}$ & $\begin{array}{l}33 \\
\text { As }\end{array}$ & $\begin{array}{l}34 \\
\text { Se }\end{array}$ & $\begin{array}{l}35 \\
\mathrm{Br}\end{array}$ & $\begin{array}{l}36 \\
\mathrm{Kr}\end{array}$ \\
\hline $\begin{array}{l}\mathbf{3 7} \\
\mathbf{R b}\end{array}$ & $\begin{array}{l}38 \\
\mathrm{Sr}\end{array}$ & $\begin{array}{l}39 \\
Y\end{array}$ & $\begin{array}{l}40 \\
\mathrm{Zr}\end{array}$ & $\begin{array}{l}41 \\
\mathrm{Nb}\end{array}$ & $\begin{array}{l}42 \\
\text { Mo }\end{array}$ & $\begin{array}{l}43 \\
\text { Tc }\end{array}$ & $\begin{array}{l}44 \\
\text { Ru }\end{array}$ & $\begin{array}{l}45 \\
\mathrm{Rh}\end{array}$ & $\begin{array}{l}46 \\
\text { Pd }\end{array}$ & & & $\begin{array}{l}48 \\
\mathrm{Cd}\end{array}$ & $\begin{array}{l}49 \\
\text { In }\end{array}$ & $\begin{array}{l}50 \\
\text { Sn }\end{array}$ & $\begin{array}{l}51 \\
\text { Sb }\end{array}$ & $\begin{array}{l}52 \\
\mathrm{Te}\end{array}$ & $\begin{array}{l}53 \\
\text { I }\end{array}$ & $\begin{array}{l}54 \\
\mathrm{Xe}\end{array}$ \\
\hline $\begin{array}{l}55 \\
\text { Cs }\end{array}$ & $\begin{array}{l}56 \\
\text { Ba }\end{array}$ & * & $\begin{array}{l}72 \\
\text { Hf }\end{array}$ & $\begin{array}{l}73 \\
\text { Ta }\end{array}$ & $\begin{array}{l}74 \\
W\end{array}$ & $\begin{array}{l}75 \\
\mathrm{Re}\end{array}$ & $\begin{array}{l}76 \\
\text { Os }\end{array}$ & $\begin{array}{l}77 \\
\text { Ir }\end{array}$ & $\begin{array}{l}78 \\
P t\end{array}$ & & & $\begin{array}{l}80 \\
\mathrm{Hg}\end{array}$ & $\begin{array}{l}81 \\
\text { T1 }\end{array}$ & $\begin{array}{l}82 \\
\mathrm{~Pb}\end{array}$ & $\begin{array}{l}83 \\
\mathrm{Bi}\end{array}$ & $\begin{array}{l}84 \\
\text { Po }\end{array}$ & $\begin{array}{l}85 \\
\text { At }\end{array}$ & $\begin{array}{l}86 \\
\text { Rn }\end{array}$ \\
\hline $\begin{array}{l}87 \\
\text { Fr }\end{array}$ & $\begin{array}{l}88 \\
\mathrm{Ra}\end{array}$ & $\dagger$ & & & & & & & & & & & & & & & & \\
\hline & & $\begin{array}{l}* 57 \\
\mathbf{L a}\end{array}$ & $\frac{58}{\mathrm{Ce}}$ & $\begin{array}{l}59 \\
\text { Pr }\end{array}$ & $\begin{array}{l}60 \\
\mathrm{Nd}\end{array}$ & $\begin{array}{l}61 \\
\mathrm{Pm} \\
\end{array}$ & $\begin{array}{l}62 \\
\mathrm{Sm}\end{array}$ & & & & $\begin{array}{l}65 \\
\mathrm{~Tb}\end{array}$ & $\begin{array}{l}66 \\
\text { D. }\end{array}$ & & $\begin{array}{l}67 \\
\text { Ho }\end{array}$ & $\begin{array}{l}68 \\
\text { Er }\end{array}$ & $\begin{array}{l}62 \\
\mathrm{Tm}\end{array}$ & $\begin{array}{l}70 \\
Y b\end{array}$ & $\begin{array}{l}71 \\
\mathrm{Lu}\end{array}$ \\
\hline & & $\begin{array}{l}\text { †89 } \\
\text { Ac }\end{array}$ & $\begin{array}{l}90 \\
\text { Th }\end{array}$ & $\begin{array}{l}91 \\
\mathrm{~Pa}\end{array}$ & $\begin{array}{l}92 \\
\mathrm{U}\end{array}$ & & & & & & & & & & & & & \\
\hline & & & & & & & & & & & & & & & & & & \\
\hline & & & & & & & & & & & & & & & & & & \\
\hline & & & & & & & & & & & & & & & & & & \\
\hline & & & & & & & & & 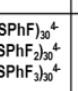 & & & & & & & & & \\
\hline & & & & & & & & & & & & & & & & & & \\
\hline & & & & & & & & & & & & & & & & & & \\
\hline & & & & & & & & & & & & & & & & & & \\
\hline & & & & & & & & & & & & & & & & & & \\
\hline & & & & & & & & & & & & & & & & & & \\
\hline
\end{tabular}


Figure 10. Elemental periodic table (top) along with a proposed clusterograph of Ag clusters (bottom). The yellow, green, red, blue, and violet shading highlights the similarities in the properties of different Ag clusters at the local or regional levels.

\section{Author information}

Corresponding author

*E-mail: osman.bakr@kaust.edu.sa

Notes

The authors declare no competing financial interest.

\section{Biographies}

Chakra P. Joshi is currently working at the KAUST Functional Nanomaterials Lab. His research interests include Ag cluster syntheses and their characterization.

Megalamane S. Bootharaju is currently pursuing his post-doctoral study at the KAUST Functional Nanomaterials Lab. His main research interests include investigating the ligand exchange of metal clusters both theoretically and experimentally.

Dr. Osman M. Bakr is currently working as an assistant professor of materials science and engineering at KAUST. His broad research interests include the fabrication, characterization, and photovoltaic applications of nanomaterials. For further information about the research work in Dr. Bakr's lab, please visit http://funl.kaust.edu.sa/Pages/Home.aspx

\section{Acknowledgements}

We acknowledge using KAUST resources.

\section{References}

(1) Feynman, R. P. There is Plenty of Room at the Bottom. Caltech Eng. Sci. 1960, 23, 2236.

(2) Becker, E. W.; Bier, K.; Henkes, W. Strahlen aus kondensierten Atomen und Molekeln im Hochvakuum. Z. Phys. 1956, 146, 333-338.

(3) Negishi, Y.; Nobusada, K.; Tsukuda, T. Glutathione-Protected Gold Clusters Revisited: Bridging the Gap between Gold(I)-Thiolate Complexes and Thiolate-Protected Gold Nanocrystals. J. Am. Chem. Soc. 2005, 127, 5261-5270.

(4) Kumar, S.; Bolan, M. D.; Bigioni, T. P. Glutathione-Stabilized Magic-Number Silver Cluster Compounds. J. Am. Chem. Soc. 2010, 132, 13141-13143.

(5) Schaaff, T. G.; Knight, G.; Shafigullin, M. N.; Borkman, R. F.; Whetten, R. L. Isolation and Selected Properties of a 10.4k Da Gold:Glutathione Cluster Compound. J. Phys. Chem. B 1998, 102, 10643-10646. 
(6) Price, R. C.; Whetten, R. L. All-Aromatic, Nanometer-Scale, Gold-Cluster Thiolate Complexes. J. Am. Chem. Soc. 2005, 127, 13750-13751.

(7) Jin, R. Atomically Precise Metal Nanoclusters: Stable Sizes and Optical Properties. Nanoscale 2015, 7, 1549-1565.

(8) Knight, W.; Clemenger, K.; de Heer, W.; Saunders, W.; Chou, M.; Cohen, M. Electronic Shell Structure and Abundances of Sodium Clusters. Phys. Rev. Lett. 1984, 52, 2141-2143.

(9) Kroto, H. W.; Heath, J. R.; O'Brien, S. C.; Curl, R. F.; Smalley, R. E. C60:

Buckminsterfullerene. Nature 1985, 318, 162-163.

(10) Jin, R.; Cao, Y.; Mirkin, C. A.; Kelly, K. L.; Schatz, G. C.; Zheng, J. G. Photoinduced Conversion of Silver Nanospheres to Nanoprisms. Science 2001, 294, 1901-1903.

(11) Eustis, S.; El-Sayed, M. A. Why Gold Nanoparticles are More Precious than Pretty Gold: Noble Metal Surface Plasmon Resonance and its Enhancement of the Radiative and Nonradiative Properties of Nanocrystals of Different Shapes. Chem. Soc. Rev. 2006, 35, 209-217.

(12) Faraday, M. The Bakerian Lecture: Experimental Relations of Gold (and Other Metals) to Light. Phil. Trans. R. Soc. Lond. 1857, 147, 145-181.

(13) Turkevich, J.; Stevenson, P. C.; Hillier, J. A Study of the Nucleation and Growth Processes in the Synthesis of Colloidal Gold. Discuss. Faraday Soc. 1951, 11, 55-75.

(14) McPartlin, M.; Mason, R.; Malatesta, L. Novel Cluster Complexes of Gold(0)-gold(I). J. Chem. Soc. D: Chem. Commun. 1969, 334-334.

(15) Gutrath, B. S.; Englert, U.; Wang, Y.; Simon, U. A Missing Link in Undecagold Cluster Chemistry: Single-Crystal X-ray Analysis of $\left[\mathrm{Au}_{11}\left(\mathrm{P} \mathrm{Ph}_{3}\right)_{7} \mathrm{Cl}_{3}\right]$. Eur. J. Inorg. Chem. 2013, 2013, 2002-2006.

(16) Brust, M.; Walker, M.; Bethell, D.; Schiffrin, D. J.; Whyman, R. Synthesis of Thiolderivatised Gold Nanoparticles in a Two-phase Liquid-Liquid System. J. Chem. Soc., Chem. Commun. 1994, 801-802.

(17) Schaaff, T. G.; Shafigullin, M. N.; Khoury, J. T.; Vezmar, I.; Whetten, R. L. Properties of a Ubiquitous 29k Da Au:S R Cluster Compound. J. Phys. Chem. B 2001, 105, 8785-8796.

(18) Huang, T.; Murray, R. W. Luminescence of Tiopronin Monolayer-Protected Silver Clusters Changes To That of Gold Clusters upon Galvanic Core Metal Exchange. J. Phys. Chem. B 2003, 107, 7434-7440.

(19) Cathcart, N.; Mistry, P.; Makra, C.; Pietrobon, B.; Coombs, N.; Jelokhani-Niaraki, M.; Kitaev, V. Chiral Thiol-Stabilized Silver Nanoclusters with Well-Resolved Optical Transitions Synthesized by a Facile Etching Procedure in Aqueous Solutions. Langmuir 2009, 25, 58405846.

(20) Bakr, O. M.; Amendola, V.; Aikens, C. M.; Wenseleers, W.; Li, R.; Dal Negro, L.; Schatz, G. C.; Stellacci, F. Silver Nanoparticles with Broad Multiband Linear Optical Absorption. Angew. Chem. Int. Ed. 2009, 121, 6035-6040.

(21) Harkness, K. M.; Tang, Y.; Dass, A.; Pan, J.; Kothalawala, N.; Reddy, V. J.; Cliffel, D. E.; Demeler, B.; Stellacci, F.; Bakr, O. M.; McLean, J. A. $\operatorname{Ag}_{44}(\mathrm{~S} \mathrm{R})_{30}{ }^{4-}$ : A Silver-Thiolate Superatom Complex. Nanoscale 2012, 4, 4269-4274.

(22) Bertorelle, F.; Hamouda, R.; Rayane, D.; Broyer, M.; Antoine, R.; Dugourd, P.; Gell, L.; Kulesza, A.; Mitric, R.; Bonacic-Koutecky, V. Synthesis, Characterization and Optical Properties of low Nuclearity Liganded Silver Clusters: $\operatorname{Ag}_{31}(\mathrm{~S} \mathrm{G})_{19}$ and $\operatorname{Ag}_{15}(\mathrm{~S} \mathrm{G})_{11}$. Nanoscale 2013, 5, 5637-5643. 
(23) Guo, J.; Kumar, S.; Bolan, M.; Desireddy, A.; Bigioni, T. P.; Griffith, W. P. Mass Spectrometric Identification of Silver Nanoparticles: The Case of $\operatorname{Ag}_{32}(\mathrm{~S} \mathrm{G})_{19}$. Anal. Chem. 2012, 84, 5304-5308.

(24) Udaya Bhaskara Rao, T.; Pradeep, T. Luminescent $\mathrm{Ag}_{7}$ and $\mathrm{Ag}_{8}$ Clusters by Interfacial Synthesis. Angew. Chem. Int. Ed. 2010, 49, 3925-3929.

(25) Baksi, A.; Bootharaju, M. S.; Chen, X.; Häkkinen, H.; Pradeep, T. $\operatorname{Ag}_{11}(\mathrm{~S} \text { G) })_{7}$ : A New Cluster Identified by Mass Spectrometry and Optical Spectroscopy. J. Phys. Chem. C 2014, 118, 21722-21729.

(26) Dhayal, R. S.; Liao, J.-H.; Liu, Y.-C.; Chiang, M.-H.; Kahlal, S.; Saillard, J.-Y.; Liu, C. W. $\left[\mathrm{Ag}_{21}\left\{\mathrm{~S}_{2} \mathrm{P}(\mathrm{O} i \mathrm{Pr})_{2}\right\}_{12}\right]^{+}$: An Eight-Electron Superatom. Angew. Chem. Int. Ed. 2015, 54, 3702-3706.

(27) Jadzinsky, P. D.; Calero, G.; Ackerson, C. J.; Bushnell, D. A.; Kornberg, R. D. Structure of a Thiol Monolayer-Protected Gold Nanoparticle at $1.1 \AA$ Resolution. Science 2007, 318, 430433.

(28) Desireddy, A.; Conn, B. E.; Guo, J.; Yoon, B.; Barnett, R. N.; Monahan, B. M.;

Kirschbaum, K.; Griffith, W. P.; Whetten, R. L.; Landman, U.; Bigioni, T. P. Ultrastable Silver Nanoparticles. Nature 2013, 501, 399-402.

(29) Yang, H.; Wang, Y.; Huang, H.; Gell, L.; Lehtovaara, L.; Malola, S.; Häkkinen, H.;

Zheng, N. All-Thiol-Stabilized $\mathrm{Ag}_{44}$ and $\mathrm{Au}_{12} \mathrm{Ag}_{32}$ Nanoparticles with Single-Crystal Structures. Nat. Commun. 2013, 4.

(30) Martins, J. L.; Car, R.; Buttet, J. Variational Spherical Model of Small Metallic Particles. Surf. Sci. 1981, 106, 265-271.

(31) de Heer, W. A. The Physics of Simple Metal Clusters: Experimental Aspects and Simple Models. Rev. Mod. Phys. 1993, 65, 611-676.

(32) Roach, P. J.; Woodward, W. H.; Castleman, A. W.; Reber, A. C.; Khanna, S. N.

Complementary Active Sites Cause Size-Selective Reactivity of Aluminum Cluster Anions with Water. Science 2009, 323, 492-495.

(33) Walter, M.; Akola, J.; Lopez-Acevedo, O.; Jadzinsky, P. D.; Calero, G.; Ackerson, C. J.; Whetten, R. L.; Grönbeck, H.; Häkkinen, H. A Unified View of Ligand-Protected Gold Clusters as Superatom Complexes. Proc. Natl. Acad. Sci. 2008, 105, 9157-9162.

(34) Leuchtner, R. E.; Harms, A. C.; Castleman, A. W. Thermal Metal Cluster Anion Reactions: Behavior of Aluminum Clusters with Oxygen. J. Chem. Phys. 1989, 91, 2753-2754. (35) Zhu, M.; Aikens, C. M.; Hollander, F. J.; Schatz, G. C.; Jin, R. Correlating the Crystal Structure of A Thiol-Protected $\mathrm{Au}_{25}$ Cluster and Optical Properties. J. Am. Chem. Soc. 2008, $130,5883-5885$.

(36) Qian, H.; Eckenhoff, W. T.; Zhu, Y.; Pintauer, T.; Jin, R. Total Structure Determination of Thiolate-Protected $\mathrm{Au}_{38}$ Nanoparticles. J. Am. Chem. Soc. 2010, 132, 8280-8281.

(37) Udayabhaskararao, T.; Bootharaju, M. S.; Pradeep, T. Thiolate-Protected $\mathrm{Ag}_{32}$ Clusters: Mass Spectral Studies of Composition and Insights into the Ag-Thiolate Structure from N M R. Nanoscale 2013, 5, 9404-9411.

(38) Clemenger, K. Ellipsoidal Shell Structure in Free-electron Metal Clusters. Phys. Rev. B 1985, 32, 1359-1362.

(39) Mackay, A. A Dense Non-crystallographic Packing of Equal Spheres. Acta Crystallogr. 1962, 15, 916-918. 
(40) Luo, Z.; Gamboa, G. U.; Smith, J. C.; Reber, A. C.; Reveles, J. U.; Khanna, S. N.; Castleman, A. W. Spin Accommodation and Reactivity of Silver Clusters with Oxygen: The Enhanced Stability of $\mathrm{Ag}_{13}{ }^{-}$. J. Am. Chem. Soc. 2012, 134, 18973-18978.

(41) Martin, T. P. Shells of Atoms. Phys. Rep. 1996, 273, 199-241.

(42) Rao, T. U. B.; Nataraju, B.; Pradeep, T. Ag 9 Quantum Cluster through a Solid-State Route. J. Am. Chem. Soc. 2010, 132, 16304-16307.

(43) AbdulHalim, L. G.; Kothalawala, N.; Sinatra, L.; Dass, A.; Bakr, O. M. Neat and Complete: Thiolate-Ligand Exchange on a Silver Molecular Nanoparticle. J. Am. Chem. Soc. 2014, 136, 15865-15868.

(44) Choi, J.-P.; Fields-Zinna, C. A.; Stiles, R. L.; Balasubramanian, R.; Douglas, A. D.; Crowe, M. C.; Murray, R. W. Reactivity of $\left[\mathrm{Au}_{25}\left(\mathrm{~S} \mathrm{C} \mathrm{H}_{2} \mathrm{C} \mathrm{H}_{2} \mathrm{Ph}\right)_{18}\right]^{1-}$ Nanoparticles with Metal Ions. J. Phys. Chem. C 2010, 114, 15890-15896.

(45) Sarkar, S.; Chakraborty, I.; Panwar, M. K.; Pradeep, T. Isolation and Tandem Mass Spectrometric Identification of a Stable Monolayer Protected Silver-Palladium Alloy Cluster. $J$. Phys. Chem. Lett. 2014, 5, 3757-3762.

(46) Biltek, S. R.; Mandal, S.; Sen, A.; Reber, A. C.; Pedicini, A. F.; Khanna, S. N. Synthesis and Structural Characterization of an Atom-Precise Bimetallic Nanocluster, $\mathrm{Ag}_{4} \mathrm{Ni}_{2}(\mathrm{D} \mathrm{M} \mathrm{S} \mathrm{A})_{4}$. J. Am. Chem. Soc. 2012, 135, 26-29.

(47) Biltek, S. R.; Sen, A.; Pedicini, A. F.; Reber, A. C.; Khanna, S. N. Isolation and Structural Characterization of a Silver-Platinum Nanocluster, $\mathrm{Ag}_{4} \mathrm{Pt}_{2}(\mathrm{D} \mathrm{M} \mathrm{S} \mathrm{A})_{4}$. J. Phys. Chem. A 2014, 118, 8314-8319.

(48) AbdulHalim, L. G.; Ashraf, S.; Katsiev, K.; Kirmani, A. R.; Kothalawala, N.; Anjum, D. H.; Abbas, S.; Amassian, A.; Stellacci, F.; Dass, A.; Hussain, I.; Bakr, O. M. A Scalable Synthesis of Highly Stable and Water Dispersible $\operatorname{Ag}_{44}(\mathrm{~S} R)_{30}$ Nanoclusters. J. Mater. Chem. A 2013, $1,10148-10154$.

(49) Yao, C.; Chen, J.; Li, M.-B.; Liu, L.; Yang, J.; Wu, Z. Adding Two Active Silver Atoms on $\mathrm{Au}_{25}$ Nanoparticle. Nano Lett. 2015, 15, 1281-1287.

(50) Chen, W.-T.; Hsu, Y.-J.; Kamat, P. V. Realizing Visible Photoactivity of Metal Nanoparticles: Excited-State Behavior and Electron-Transfer Properties of Silver $\left(\mathrm{Ag}_{8}\right)$ Clusters. J. Phys. Chem. Lett. 2012, 3, 2493-2499.

(51) Desireddy, A.; Kumar, S.; Guo, J.; Bolan, M. D.; Griffith, W. P.; Bigioni, T. P. Temporal Stability of Magic-Number Metal Clusters: Beyond the Shell Closing Model. Nanoscale 2013, 5, 2036-2044.

(52) Kumara, C.; Aikens, C. M.; Dass, A. X-ray Crystal Structure and Theoretical Analysis of $\mathrm{Au}_{25}-\mathrm{x} \mathrm{Ag} \mathrm{Ag}_{\mathrm{x}}\left(\mathrm{S} \mathrm{H}_{2} \mathrm{C} \mathrm{H}_{2} \mathrm{Ph}\right)_{18}{ }^{-}$Alloy. J. Phys. Chem. Lett. 2014, 5, 461-466.

(53) Udayabhaskararao, T.; Sun, Y.; Goswami, N.; Pal, S. K.; Balasubramanian, K.; Pradeep, $\mathrm{T}$. $\mathrm{Ag}_{7} \mathrm{Au}_{6}$ : A 13-Atom Alloy Quantum Cluster. Angew. Chem. Int. Ed. 2012, 51, 2155-2159.

(54) Henglein, A. Mechanism of Reactions on Colloidal Microelectrodes and Size Quantization Effects. In Electrochemistry I I, Steckhan, E., Ed. Springer Berlin Heidelberg: 1988; Vol. 143, pp 113-180.

(55) Xu, Q.-Q.; Dong, X.-Y.; Huang, R.-W.; Li, B.; Zang, S.-Q.; Mak, T. C. W. A Thermochromic Silver Nanocluster Exhibiting Dual Emission Character. Nanoscale 2015, 7, 1650-1654.

(56) Díez, I.; Pusa, M.; Kulmala, S.; Jiang, H.; Walther, A.; Goldmann, A. S.; Müller, A. H. E.; Ikkala, O.; Ras, R. H. A. Color Tunability and Electrochemiluminescence of Silver Nanoclusters. Angew. Chem. Int. Ed. 2009, 48, 2122-2125. 
(57) Bootharaju, M. S.; Burlakov, V. M.; Besong, T. M. D.; Joshi, C. P.; AbdulHalim, L. G.; Black, D.; Whetten, R.; Goriely, A.; Bakr, O. M. Reversible Size Control of Silver Nanoclusters via Ligand-exchange. Chem. Mater. 2015.

(58) Cao, T.; Jin, S.; Wang, S.; Zhang, D.; Meng, X.; Zhu, M. A Comparison of the Chiral Counterion, Solvent, and Ligand Used to Induce a Chiroptical Response from $\mathrm{Au}_{25}$ Nanoclusters. Nanoscale 2013, 5, 7589-7595.

(59) Farrag, M.; Tschurl, M.; Heiz, U. Chiral Gold and Silver Nanoclusters: Preparation, Size Selection, and Chiroptical Properties. Chem. Mater. 2013, 25, 862-870.

(60) Chakraborty, I.; Pradeep, T. Reversible Formation of $\mathrm{Ag}_{44}$ From Selenolates. Nanoscale 2014, 6, 14190-14194.

(61) Shichibu, Y.; Negishi, Y.; Watanabe, T.; Chaki, N. K.; Kawaguchi, H.; Tsukuda, T. Biicosahedral Gold Clusters $\left[\mathrm{Au}_{25}\left(\mathrm{P} \mathrm{Ph}_{3}\right)_{10}\left(\mathrm{~S} \mathrm{C}_{\mathrm{n}} \mathrm{H}_{2 \mathrm{n}+1}\right)_{5} \mathrm{Cl}_{2}\right]^{2+}(\mathrm{n}=2-18)$ : A Stepping Stone to Cluster-Assembled Materials. J. Phys. Chem. C 2007, 111, 7845-7847.

(62) Qian, H.; Zhu, M.; Lanni, E.; Zhu, Y.; Bier, M. E.; Jin, R. Conversion of Polydisperse Au Nanoparticles into Monodisperse $\mathrm{Au}_{25}$ Nanorods and Nanospheres. J. Phys. Chem. C 2009, 113, 17599-17603.

(63) Zhu, Y.; Qian, H.; Das, A.; Jin, R. Comparison of the Catalytic Properties of 25-Atom Gold Nanospheres and Nanorods. Chin. J. Catal. 2011, 32, 1149-1155.

(64) Yang, H.; Lei, J.; Wu, B.; Wang, Y.; Zhou, M.; Xia, A.; Zheng, L.; Zheng, N. Crystal Structure of a Luminescent Thiolated Ag Nanocluster with an Octahedral $\mathrm{Ag}_{6}{ }^{4+}$ Core. Chem. Commun. 2013, 49, 300-302.

(65) Yang, H.; Wang, Y.; Zheng, N. Stabilizing Subnanometer $\operatorname{Ag}(0)$ Nanoclusters by Thiolate and Diphosphine Ligands and Their Crystal Structures. Nanoscale 2013, 5, 2674-2677.

(66) Tang, Q.; Ouyang, R.; Tian, Z.; Jiang, D.-e. The Ligand Effect on the Isomer Stability of $\mathrm{Au}_{24}(\mathrm{~S} \mathrm{R})_{20}$ Clusters. Nanoscale 2015, 7, 2225-2229.

(67) Tlahuice-Flores, A.; Whetten, R. L.; Jose-Yacaman, M. Ligand Effects on the Structure and the Electronic Optical Properties of Anionic $\mathrm{Au}_{25}(\mathrm{~S} \mathrm{R})_{18}$ Clusters. J. Phys. Chem. C 2013, $117,20867-20875$.

(68) Lopez-Acevedo, O.; Tsunoyama, H.; Tsukuda, T.; Häkkinen, H.; Aikens, C. M. Chirality and Electronic Structure of the Thiolate-Protected $\mathrm{Au}_{38}$ Nanocluster. J. Am. Chem. Soc. 2010, $132,8210-8218$.

(69) Chakraborty, I.; Govindarajan, A.; Erusappan, J.; Ghosh, A.; Pradeep, T.; Yoon, B.; Whetten, R. L.; Landman, U. The Superstable 25k Da Monolayer Protected Silver Nanoparticle: Measurements and Interpretation as an Icosahedral $\mathrm{Ag}_{152}\left(\mathrm{~S} \mathrm{C} \mathrm{H}_{2} \mathrm{C} \mathrm{H}_{2} \mathrm{Ph}\right)_{60}$ Cluster. Nano Lett. 2012, 12, 5861-5866.

(70) Kubo, R. Electronic Properties of Metallic Fine Particles. I. J. Phys. Soc. Japan 1962, 17, 975.

(71) Buceta, D.; Piñeiro, Y.; Vázquez-Vázquez, C.; Rivas, J.; López-Quintela, M. Metallic Clusters: Theoretical Background, Properties and Synthesis in Microemulsions. Catalysts 2014, 4, 356-374.

(72) Bigioni, T. P.; Whetten, R. L.; Dag, Ö. Near-Infrared Luminescence from Small Gold Nanocrystals. J. Phys. Chem. B 2000, 104, 6983-6986.

(73) Wilcoxon, J. P.; Martin, J. E.; Parsapour, F.; Wiedenman, B.; Kelley, D. F. Photoluminescence from Nanosize Gold Clusters. J. Chem. Phys. 1998, 108, 9137-9143. 
(74) Link, S.; Beeby, A.; FitzGerald, S.; El-Sayed, M. A.; Schaaff, T. G.; Whetten, R. L. Visible to Infrared Luminescence from a 28-Atom Gold Cluster. J. Phys. Chem. B 2002, 106, 3410-3415.

(75) Zheng, J.; Zhang, C.; Dickson, R. M. Highly Fluorescent, Water-Soluble, Size-Tunable Gold Quantum Dots. Phys. Rev. Lett. 2004, 93, 077402.

(76) Zheng, J.; Dickson, R. M. Individual Water-Soluble Dendrimer-Encapsulated Silver Nanodot Fluorescence. J. Am. Chem. Soc. 2002, 124, 13982-13983.

(77) Yuan, X.; Setyawati, M. I.; Tan, A. S.; Ong, C. N.; Leong, D. T.; Xie, J. Highly Luminescent Silver Nanoclusters with Tunable Emissions: Cyclic Reduction-Decomposition Synthesis and Antimicrobial Properties. NPG Asia Mater. 2013, 5, e39.

(78) Li, B.; Huang, R.-W.; Qin, J.-H.; Zang, S.-Q.; Gao, G.-G.; Hou, H.-W.; Mak, T. C. W. Thermochromic Luminescent Nest-Like Silver Thiolate Cluster. Chem. Eur. J. 2014, 20, 1241612420.

(79) Wu, Z.; Jin, R. On the Ligand's Role in the Fluorescence of Gold Nanoclusters. Nano Lett. 2010, 10, 2568-2573.

(80) Pelton, M.; Tang, Y.; Bakr, O. M.; Stellacci, F. Long-Lived Charge-Separated States in Ligand-Stabilized Silver Clusters. J. Am. Chem. Soc. 2012, 134, 11856-11859.

(81) Chin, P. T. K.; Linden, M. v. d.; Harten, E. J. v.; Barendregt, A.; Rood, M. T. M.; Koster, A. J.; Leeuwen, F. W. B. v.; Donega, C. d. M.; Heck, A. J. R.; Meijerink, A. Enhanced Luminescence of Ag Nanoclusters via Surface Modification. Nanotechnology 2013, 24, 075703. (82) Yao, Q.; Yu, Y.; Yuan, X.; Yu, Y.; Zhao, D.; Xie, J.; Lee, J. Y. Counterion-Assisted Shaping of Nanocluster Supracrystals. Angew. Chem. Int. Ed. 2015, 54, 184-189.

(83) Das, A.; Li, T.; Nobusada, K.; Zeng, C.; Rosi, N. L.; Jin, R. Nonsuperatomic $\left[\mathrm{Au}_{23}\left(\mathrm{~S} \mathrm{C}_{6}\right.\right.$ $\left.\left.\mathrm{H}_{11}\right)_{16}\right]^{-}$Nanocluster Featuring Bipyramidal $\mathrm{Au}_{15}$ Kernel and Trimeric $\mathrm{Au}_{3}(\mathrm{~S} R)_{4}$ Motif. J. Am. Chem. Soc. 2013, 135, 18264-18267.

(84) Zeng, C.; Chen, Y.; Kirschbaum, K.; Appavoo, K.; Sfeir, M. Y.; Jin, R. Structural Patterns at All Scales in a Nonmetallic Chiral $\mathrm{Au}_{133}(\mathrm{~S} R)_{52}$ Nanoparticle. Science Advances 2015, 1 .

(85) Jena, P. Beyond the Periodic Table of Elements: The Role of Superatoms. J. Phys. Chem. Lett. 2013, 4, 1432-1442.

(86) Luo, Z.; Castleman, A. W. Special and General Superatoms. Acc. Chem. Res. 2014, 47, 2931-2940.

Quotes:

1. Geometric shell closing is also applied to explain the cluster stability. Depending on the geometric shape, e.g., cubic, tetrahedral, octahedral, or icosahedral, certain numbers of building units are required to form a closed geometry

2. For tuning Ag cluster size, researchers should look at those aryl thiols that have substitution adjacent to the thiol group. This subtle change in ligand could unlock the key for other size Ag clusters

3. Magic size clusters maintain a magic ratio of approximately 2 free electrons for every 3 metal atoms with some intercept 